\title{
HEDGING OPTIONS WITH AN ILLIQUID UNDERLYING AND NON-PROBABILISTIC OPTION PRICING IN PRACTICE
}

\author{
by \\ Nolan Nicholls \\ Bachelor of Science, Queen's University, 2013 \\ Master of Science, Western University, 2014 \\ A thesis \\ presented to Ryerson University \\ in partial fulfilment \\ of the requirements for the Degree of \\ Master of Science \\ in the program of \\ Applied Mathematics
}

Toronto, Ontario, Canada, 2016

(C) Nolan Nicholls 2016 
AUTHOR'S DECLARATION FOR ELECTRONIC SUBMISSION OF A THESIS

I hereby declare that I am the sole author of this thesis. This is a true copy of the thesis, including any required final revisions, as accepted by my examiners.

I authorize Ryerson University to lend this thesis to other institutions or individuals for the purpose of scholarly research.

I further authorize Ryerson University to reproduce this thesis by photocopying or by other means, in total or in part, at the request of other institutions or individuals for the purpose of scholarly research.

I understand that my thesis may be made electronically available to the public. 
Hedging Options with an Illiquid Underlying and Non-Probabilistic Option Pricing in Practice

Master of Science 2016

Nolan Nicholls

Applied Mathematics

Ryerson University

We compare three different dynamic hedging strategies for the purchase or sale of a bundle of European options to profit from volatility arbitrage. The investor will "cross hedge" with a stock highly correlated with the untraded underlying. The first strategy maximizes terminal utility, the second minimizes the variance of the incremental profit, and the third is the adjusted Black-Scholes strategy. We note that the nature of cross hedging results in significant potential for losses. We study the robustness of the strategies to misspecification of parameters by the investor and find that the first two strategies are more robust to parameter misspecification. On a different subject, we then attempt to find profit opportunities by pricing options using a simple non-probabilistic model. We find a situation where an investor willing to take risks can profit, but a more cautious investor cannot. We also derive basic non-probabilistic volatility arbitrage results. 


\section{Acknowledgements}

Many thanks to my two supervisors Dr. Sebastian Ferrando and Dr. Alexey

Rubtsov for their patient editing and helpful suggestions. Also, I am appreciative

to my officemate Andrew Fleck for his contributions to the non-probabilistic

coding. 


\section{TABLE OF CONTENTS}

Declaration ............................. ii

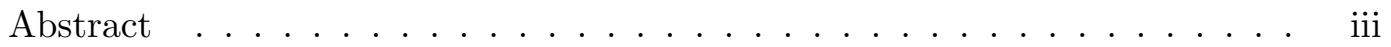

Acknowledgments .......................... iv

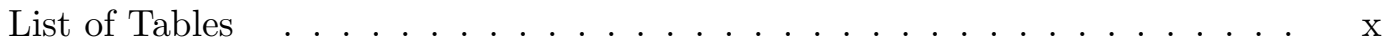

List of Figures . . . . . . . . . . . . . . . . xiii

List of Appendices ...................... . xiv

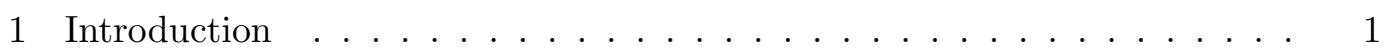

2 Delta Hedging and Volatility Arbitrage . . . . . . . . . . . . 5

2.1 Introduction . . . . . . . . . . . . . . 5

2.2 Delta Hedging with $\sigma^{a} \ldots \ldots \ldots \ldots \ldots$

2.3 Delta Hedging with $\sigma^{i} \ldots \ldots \ldots \ldots$. . . . . . . . . . . 11

2.4 Delta Hedging with $\sigma^{h}$ and Extensions . . . . . . . . . . . . . 13

3 Hedging Illiquid claims and Volatility Arbitrage _. . . . . . . . . 15

3.1 Introduction . . . . . . . . . . . . . . . . 15

3.2 Setting . . . . . . . . . . . . . . . . . 16

3.3 Two Pricing Approaches in Incomplete Markets . . . . . . . . . . . . 18 
3.4 Hedging Strategy 1 - Maximizing Utility of Terminal Wealth _ . . . 21

3.5 Hedging Strategy 2 - Minimizing Portfolio Variance . . . . . . . . . . 22

3.6 Hedging Strategy 3 - Adjusted Black-Scholes . . . . . . . . . . . . . 24

3.7 Volatility Arbitrage in an Incomplete Market . . . . . . . . . . . 25

3.8 Comparing the Hedging Strategies - Comparing Incremental Profits 27

3.9 Comparing the Hedging Strategies - Comparing Total Profits . . . . 36

3.10 Comparing the Hedging Strategies - Robustness to Parameter Misspecification - Profit Distribution . . . . . . . . . . . 44

3.11 Comparing the Hedging Strategies - Robustness to Parameter Misspecification - Utility Loss . . . . . . . . . . . . . . 51

4 Non-Probabilistic Option Pricing _. . . . . . . . . . . . . 56

4.1 Introduction to Non-Probabilistic Models - BJN Model . . . . . . . . 56

4.2 The M0+Time Model . . . . . . . . . . . . . . . . . 63

4.3 M0 Model - Parameter Estimation . . . . . . . . . . . . . . . 65

4.4 Pricing Options using Historic Data . . . . . . . . . . . . . 67

4.5 Volatility Arbitrage in BJN Framework . . . . . . . . . . . . 72

A Delta Hedging and Volatility Arbitrage . . . . . . . . . . . 76

B Hedging Illiquid Claims and Volatility Arbitrage . . . . . . . . . . . 78

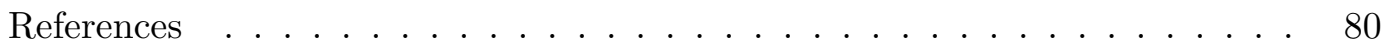




\section{LIST OF TABLES}

2.1 The evolution of the value of the portfolio over a single time increment,but before rebalancing, when hedging with $\Delta_{t}^{a}$. Note that $V^{i}=\mathrm{BS}\left(t, S ; 0, \sigma^{i}\right), \Delta^{a}=\Delta\left(t, S ; 0, \sigma^{a}\right)$ and $d V^{i}=d V\left(t, S ; 0, \sigma^{i}\right)$. We have suppressed the function argument notation for simplicity. Note that we evaluate the option position using $\sigma^{i} \ldots \ldots \ldots$

3.1 The stock and option parameters used in this section unless otherwise specified. We consider an investor with $\gamma=0.0001$, similar to the investor in Monoyios (2004) . . . . . . . . . . . . .

3.2 The different valuations for the bundle of options resulting from different values of $\rho$ and $\eta$. Here, the larger $\eta$ results in a larger option value, meaning an investor can attempt to profit from a misspecification by buying call options. . . . . . . . . . . . . . .

3.3 Properties of the incremental profit distribution. The mean is fairly large compared to the standard deviation and thus the investor sees smooth profit curves as in the right hand side of Figure 2.1. The incremental profit is calculated as in Eqn.(3.6). Statistics are generated from 10000 trajectory pair simulations. Note that the properties for a single trajectory pair will be path dependent. . . . . . . . . . 
3.4 Properties of the profit distribution on an incremental basis with a slightly less significant correlation for each of the hedging strategies. The standard deviation is now noticeably larger than the mean, meaning that the noise has made it difficult to justify any particular strategy over the other. These results are from the simulation of 10000 trajectory pairs with 500 uniform rehedging times. Note that we consider the modified Minimal Local Variance Strategy here from Eqn.(3.7) and evaluate the other two with $\eta^{i}$. The incremental profit is calculated as in Eqn.(3.6). Statistics are generated from 10 000 trajectory pair simulations. Note that the properties for a single trajectory pair will be path dependent. . . . . . . . . . .

3.5 Stock and option parameters used in the first part Section 3.9 unless otherwise specified. . . . . . . . . . . . . . . . 36

3.6 Different valuations for the bundle of call options resulting from different values of $\rho$ and $\eta \ldots \ldots \ldots \ldots \ldots \ldots$

3.7 The stock and option parameters used in the rest of this section unless otherwise specified. . . . . . . . . . . . . .

3.8 The different valuations for the bundle of puts resulting from different values of $\eta$. Here, the larger $\eta$ results in a larger option value, meaning can investor can profit from a misspecification by selling call options. 
3.9 The distributions of the total profit when hedging the sale of a bundle of 500 put options with the stock and option parameters given in Table 3.7, with different values for $\eta \ldots \ldots \ldots \ldots$

3.10 The distributions of the total profit when hedging the sale of a bundle of 500 put options with the stock and option parameters given in Table 3.7, with different values for $\sigma \ldots \ldots \ldots \ldots \ldots$

3.11 The distributions of the total profit when hedging the sale of a bundle of 500 put options with the stock and option parameters given in Table 3.7, with different values for $v \ldots \ldots \ldots \ldots \ldots$

3.12 The distributions of the total profit when hedging the sale of a bundle of 500 put options with the stock and option parameters given in Table 3.7, with different values for $\mu \ldots \ldots \ldots$

3.13 The distributions of the total profit when hedging the sale of a bundle of 500 put options with the stock and option parameters given in Table 3.7, with different values for $\rho \ldots \ldots \ldots \ldots$

3.14 Utility loss due to misspecification of $\eta$ when hedging the sale of 500

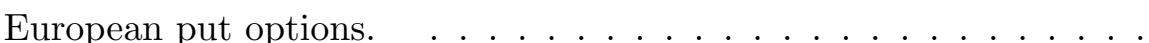

3.15 Utility loss due to misspecification of $\sigma$ when hedging the sale of 500 European put options. . . . . . . . . . . . . . 54

3.16 Utility loss due to misspecification of $v$ when hedging the sale of 500 European put options. $\ldots \ldots \ldots \ldots \ldots$ 
3.17 Utility loss due to misspecification of $\mu$ when hedging the sale of 500

European put options. . . . . . . . . . . . . . . . 55

3.18 Utility loss due to misspecification of $\rho$ when hedging the sale of 500

European put options. . . . . . . . . . . . . . . 55 


\section{LIST OF FIGURES}

2.1 The Profit Curves when delta hedging a European call option with Left: $\sigma^{a}$ Right: $\quad \sigma^{i}$. Parameters used are $S_{0}=50, \mu=0, \sigma^{a}=0.3$, $\sigma^{i}=0.2, K=50, r=0.05$ and $q=0$. These results are generated by simulations of the underlying stock where the investor rebalances 500 times over the life of the option. . . . . . . . . . . .

3.1 Above: Some of the profit trajectories when $\rho=0.9999$ and the stock and option parameters are as in Table 3.1. Below: Profit trajectories when $\rho=0.95$. Even with a very strong correlation the investor loses the smooth profit property. Incremental profits are calculated as in

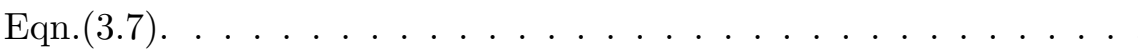

3.2 The distribution of total profit when long a bundle of European call options, $\rho=0.95$ and the investor does not hedge. The total profit is found by summing the incremental profits calculated using Eqn.(3.6).

3.3 The distribution of total profit when long a bundle of European call options, $\rho=0.95$ and the investor hedges using strategy Left: Maximal Utility, Center: Minimal Variance, Right: Adjusted BlackScholes. The total profit is found by summing the incremental profits calculated using Eqn.(3.6). . . . . . . . . . . . . . . . 
3.4 The distribution of total profit when long a bundle of European call options, $\rho=0.55$ and we hedge using strategy Left: Maximal Utility, Center: Minimal Variance, Right: Adjusted Black-Scholes. The total profit is found by summing the incremental profits calculated using Eqn.(3.6) . . . . . . . . . . . . . . . . . . . .

3.5 Distribution of the total profit when short a bundle of 100 European call options and using the hedging strategy: Left: Minimal Variance. Right: Adjusted Black-Scholes. The total profit is found by summing the incremental profits calculated using Eqn.(3.6). . . . . . . . . .

3.6 The distribution of total profit when short a bundle of European puts, $\rho=0.55$ and we hedge using strategy Top Left: Maximal Utility $\gamma=0.0001$, Top Right: Maximal Utility $\gamma=0.001$, Bottom Left: Minimal Variance, Bottom Right: Adjusted Black-Scholes. The total profit is found by summing the incremental profits calculated using Eqn.(3.6). . . . . . . . . . . . . . . . . .

3.7 The amount of money invested in the traded stock by each hedging strategy when the investor has sold 500 European call options.. The similarity between the minimal variance strategy and the maximal utility strategy $(\gamma=0.0001)$ explain why the profit results are so

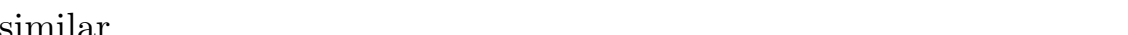


4.1 The graphical depiction of the convex hull pricing a particular node on a trajectory using all accessible node prices. . . . . . . . . . .

4.2 Six months of hourly Facebook stock prices taken between September 21, 2015 and March 21, 2016. . . . . . . . . . .

4.3 The arbitrage bounds for European call options for a risk taking investor compared with the market price. When the market price lies outside of the bounds there is the chance for arbitrage. . . . . . . 68

4.4 Top: Mapping the future trajectory onto the grid. We can see that the fairly close agreement allows an investor to be confident in obtaining a profit. Bottom: Mapping a difficult trajectory onto the grid. It is easy to see that there is much disagreement, and the investor would not be certain to profit. . . . . . . . . . . . .

4.5 The arbitrage bounds for European call options for a more cautious investor compared with the market price. When the market price lies outside of the bounds there is the chance for arbitrage. $\ldots . . . .71$ 


\section{LIST OF APPENDICES}

A1 Incremental Profit when Hedging with $\sigma^{a} \ldots \ldots \ldots 76$

A2 Total Profit Distribution when Hedging with $\sigma^{i} \ldots \ldots 76$

B1 Deriving Utility Indifference Price and Optimal Hedge. . . . . . . 78

B2 Alternative Expression for Maximal Utility Hedge. . . . . . . . . . 80 


\section{Chapter 1}

\section{INTRODUCTION}

This thesis will focus primarily on two different topics. The first will concern the hedging of European options with either the underlying stock or a stock highly correlated with the underlying (Chapters 2 and 3). Options hedging is an incredibly important investment strategy whereby an investor takes a position by purchasing or short selling some amount of stock, to reduce the risk of a position involving the purchase or sale of options. Hedging can be divided into two broad categories (Papayiannis, 2010). The first is static hedge, which an investor will construct at the onset and does not need to be adjusted with time. An example would be purchasing an option, and then immediately selling some amount of the underlying stock. The second is dynamic hedging, where an investor is constantly updating an offsetting position in the option's underlying or in an asset correlated with the underlying. An example of this is the standard Black-Scholes hedging strategy. When the hedging is done with a correlated asset, it is referred to as cross hedging. A perfect hedge will eliminate the risk of a position entirely, however, due to a number of issues such as stock price jumps, stochastic stock volatility, transaction costs or an inability to hedge continuously, such hedges are exceedingly rare. Hence, hedging strategies can be evaluated by how much uncertainty in the final result they remove. It is also 
important to consider the negatives of a particular hedging strategy, so the investor can determine if the costs are worth the benefits. For example, a hedging strategy may involve trading too much or too frequently which can result in the investor being responsible for significant transaction costs. Throughout, we will consider an investor who is attempting to take advantage of volatility arbitrage, meaning that the investor has a more accurate forecast for the future volatility than the market (Ahmad \& Wilmott, 2005). This allows an investor to identify an option as mispriced. We first summarize the main results of Ahmad and Wilmott (2005) who compare different dynamic hedging strategies and weigh the benefits and drawbacks of each (we revisit these results in Chapter 2) in a Black-Scholes complete market. In this setting, the investor is guaranteed to secure a profit if they have forecasted the volatility correctly. The two strategies differ only in what value for the volatility is used in the Black-Scholes hedging formula. In Chapter 3, we consider an investor who is unable or unwilling to trade with the option's underlying, but instead cross hedges with a second stock that is correlated with the underlying. We extend the experiment of Ahmad and Wilmott (2005), into this incomplete market framework. We will consider an investor who possesses a more accurate forecast of the future volatility of the untraded underlying, and wishes to profit from volatility arbitrage by trading with a correlated stock. We compare the results of three different hedging strategies, two of which we suggest are analogous to those presented by Ahmad and Wilmott (2005), and a third which corresponds to a naive investor who believes 
that the two stocks are perfectly correlated. Comparisons of different cross hedging strategies have been performed before (Hulley \& McWalter, 2015; Monoyios, 2004; Papayiannis, 2010), and mainly differentiated the strategies on the basis of the profit distributions each results in. Here, we will be studying each hedging strategy as a means to secure a profit from volatility arbitrage, and we aim for a comparison that is more comprehensive. We not only study the resulting profit distributions, but also test the robustness of these hedging strategies to parameter misspecification. Ahmad and Wilmott (2005) show that in the Black-Scholes world, the Black-Scholes hedging strategy can be expected to profit from volatility arbitrage, for a wide range of choices of volatility. This issues is more important when cross hedging, where there are additional parameters to estimate. The maximal utility and minimal variance strategies both require the estimation of five different parameters, including two of the notoriously difficult to estimate drift terms, while the adjusted BlackScholes strategy requires the estimation of only two. This means that the two more sophisticated strategies will give the investor more opportunities for parameter misspecification. We will compare strategy robustness by looking at the effect of misspecification of each of the parameters on profit distributions, as well as on the loss of expected terminal utility. We propose that this latter method is the most relevant for comparison, because, as we will see, all three strategies will result in significant uncertainty in final profit. For this reason, the investor's risk preferences will be of paramount importance. 
The second main portion of the thesis introduces the concept of non-probabilistic models for stock movements and option pricing. These allow an investor to assign upper and lower arbitrage price bounds to an option (Chapter 4). It has been suggested that these models are more compatible with the concepts of arbitrage, which is concerned only with events that are possible or impossible, and not their relative likelihood (Britten-Jones \& Neuberger, 1996). They also naturally incorporate jump sizes and the necessarily discontinuous nature of hedging. We review an early framework for non-probabilistic models, the Britten-Jones and Neuberger model (BJN), that requires stock trajectories consume a certain quadratic variation over the lifetime of an option. We then propose a simple, new framework, which allows for varying quadratic variations and is dependent on the operations of the investor. We argue that this new model is more practical for exploiting arbitrage opportunities than the BJN model. The main parameters of the model are easily understood and intuitive, and can be adjusted to suit the risk preferences of the investor. We use this model as well as the history of price movements for a few stocks, to price European options and compare these prices to market prices. Where possible, we identify arbitrage opportunities and attempt to translate them into profits. We also examine reasons the model can fail to capitalize on arbitrage opportunities and suggest a few extensions. 


\section{Chapter 2}

\section{DELTA HEDGING AND VOLATILITY ARBITRAGE}

\subsection{Introduction}

Volatility arbitrage is a type of statistical arbitrage that results when an investor has a forecast of the future realized volatility that he or she believe to be more accurate than the volatility implied by option prices (Ahmad \& Wilmott, 2005). Ahmad and Wilmott (2005) study how to profit from this scenario in the standard BlackScholes setting with a single, tradeable underlying, following a lognormal diffusion with constant volatility and drift. The price of the underlying asset, $\left(P_{t}\right)_{0 \leqslant t \leqslant T}$, obeys

$$
d P_{t}=\mu P_{t} d t+\sigma P_{t} d B_{t}
$$

where $\mu$ is the drift, $\sigma$ is the volatility and $\left(B_{t}\right)_{0 \leqslant t \leqslant T}$ is a standard Brownian motion. They consider a situation where an investor believes that the actual realized volatility, $\sigma^{a}$, will be different than that implied by option prices, $\sigma^{i}$. This $\sigma^{i}$ is obtained by inverting the Black-Scholes pricing formula (Eqn.(2.2) for a European call) to find the value for $\sigma$ that gives the current market price of the option. The investor will find $\sigma^{i}$ at the initial time $t_{0}$ and we will assume it remains constant until the option expiration time T. In the Black-Scholes formula for the price of a 
European call (or put) option, the volatility is the only parameter which is is not directly observable. The Black-Scholes price of a European call option with strike $K$ underlying stock volatility $\sigma$, and continuous dividends yield $q$, is

$$
C\left(P_{t}, t\right)=N\left(d_{1}\right) P_{t}-N\left(d_{2}\right) K e^{-r(T-t)},
$$

where

$$
N(x)=\frac{1}{\sqrt{2 \pi}} \int_{-\infty}^{x} e^{\frac{-s^{2}}{2}} d s
$$

and

$$
d_{1}\left(t, P_{t} ; q, \sigma\right)=\frac{\ln \left(\frac{P_{t}}{K}\right)+\left(r-q+\frac{1}{2} \sigma^{2}\right)(T-t)}{\sigma \sqrt{T-t}}, d_{2}=d_{1}-\sigma \sqrt{T-t},
$$

where $\mathrm{r}$ is the interest rate. Hence, if the investor believes that the volatility over the option's life, $\sigma^{a}$, will be different than that implied by option prices, $\sigma^{i}$, an option can be identified as being mispriced. It is the exploitation of this mispricing to obtain a profit, usually with delta hedging, that is referred to as volatility arbitrage. Ahmad and Wilmott (2005) initially consider a situation where the realized volatility will be $30 \%$ and the implied volatility of an option is $20 \%$. Because the Black-Scholes price of a European option is a monotonic increasing function of the volatility, $\mathrm{BS}\left(t, P_{t} ; q, \sigma_{1}\right)>\mathrm{BS}\left(t, S_{t} ; q, \sigma_{2}\right)$ if $\sigma_{1}>\sigma_{2}$, where $\mathrm{BS}\left(t, P_{t} ; q, \sigma\right)$ is the Black-Scholes price of an option with an underlying that pays out continuous dividend yield $q$ and volatility $\sigma$. In this scenario, the investor knows that the market has undervalued the option. To profit, Ahmad and Wilmott (2005) propose that an investor buy a European call option and delta hedge it until the expiration time T. Alternatively, if the implied volatility were larger than what the investor believes will be the actual 
volatility, then the investor could sell the option and delta hedge to profit. The usual prescription for delta hedging the purchase of a European call option, is to be short an amount of the underlying stock,$\Delta$, according to

$$
\Delta\left(t, P_{t} ; q, \sigma\right)=e^{-q t} N\left(d_{1}\left(t, P_{t} ; q, \sigma\right)\right)
$$

The investor must then decide which value for $\sigma$ to use in Eqn.(2.3). Ahmad and Wilmott (2005) examine the differences in profits that arise from choosing $\sigma^{a}$ or $\sigma^{i}$. Their main results are summarized below. Note that we take the dividend yield to be $q=0$ throughout.

\subsection{Delta Hedging with $\sigma^{a}$}

To reiterate, we are considering a situation where $\sigma^{a}>\sigma^{i}$ and so one possible investment strategy is for an investor to purchase a European call option, and delta hedge until expiration. We will see that when the investor delta hedges using $\sigma^{a}$, their total profit will be deterministic, but the incremental profit will be a random variable. Note that throughout, we use the superscript $(\ldots)^{a}$ to denote functions evaluated with $\sigma^{a}$ and $(\ldots)^{i}$ for those evaluated with $\sigma^{i}$. We also suppress much of the function argument notation below for clarity. The investor maintains a portfolio (of value $\left(\Pi_{t}\right)_{0 \leqslant t \leqslant T}$ at time $t$ ) made up of a long position in the European option, of value $\left(V_{t}\right)_{0 \leqslant t \leqslant T}$, a short position in the underlying stock (of value $\Delta_{t}^{a} P_{t}$ ), and some amount invested in a risk free bond, $\left(M_{t}\right)_{0 \leqslant t \leqslant T}$, that evolves (before rebalancing) 
according to

$$
d M_{t}=M_{t} r d t
$$

After each time increment, the investor rebalances to be short $\Delta_{t}^{a}$ of the stock and have invested an amount into the risk free bond such that

$$
M_{t}=-V_{t}^{i}+\Delta_{t}^{a} P_{t}
$$

Thus, we think of the investor as creating a new portfolio of value 0 at every rebalancing time. If the investor needs to add money into the portfolio to achieve this, we consider that amount a loss, and if the investor has to take money out of the portfolio, we consider that amount a gain. In other words, the change in the value of the portfolio after a time increment, but before rebalancing, is the investor's incremental profit $(d \Pi)$.

Theorem 2.1. When $\sigma^{a} \neq \sigma^{i}$ and the investor delta hedges the sale or purchase (at time $t_{0}$ ) of an option with $\sigma^{a}$ to take advantage of volatility arbitrage, the present value of the total profit is given by

$$
\int_{t_{0}}^{T} e^{-r\left(t-t_{0}\right)} d \Pi_{t}=\left|V_{t_{0}}^{a}-V_{t_{0}}^{i}\right|
$$

The investor will purchase the option and $\sigma^{a}>\sigma^{i}$ and sell it when $\sigma^{i}>\sigma^{a}$. Proof. We consider an investor who purchases a European call option because $\sigma^{a}>\sigma^{i}$. The proofs for other options positions are nearly identical. Table 2.1 shows the value of each component of the portfolio before and after a time increment, but before rebalancing. Note that the profit is determined on a mark-to-market basis, meaning 


\begin{tabular}{|l|c|c|}
\hline \multicolumn{2}{|c|}{ Portfolio Evolution After One Time step } \\
\hline Component & Value at Time t & Value at Time t $+\mathbf{d t}$ \\
\hline Option & $V_{t}^{i}$ & $V_{t}^{i}+d V_{t}^{i}$ \\
\hline Stock & $-P_{t} \Delta_{t}^{a}$ & $-\Delta_{t}^{a} P_{t}-\Delta_{t}^{a} d S_{t}$ \\
\hline Risk Free Bond & $-V_{t}^{i}+P_{t} \Delta_{t}^{a}$ & $\left(-V_{t}^{i}+P_{t} \Delta_{t}^{a}\right)(1+r d t)$ \\
\hline
\end{tabular}

Table 2.1: The evolution of the value of the portfolio over a single time increment,but before rebalancing, when hedging with $\Delta_{t}^{a}$. Note that $V^{i}=\operatorname{BS}\left(t, S ; 0, \sigma^{i}\right), \Delta^{a}=$ $\Delta\left(t, S ; 0, \sigma^{a}\right)$ and $d V^{i}=d V\left(t, S ; 0, \sigma^{i}\right)$. We have suppressed the function argument notation for simplicity. Note that we evaluate the option position using $\sigma^{i}$.

that the option component of the portfolio is priced using $\sigma^{i}$ in Eqn.(2.2). This is meant to represent the market's estimate of the option position value. We can see that the incremental profit will be given by

$$
d \Pi_{t}=d V_{t}^{i}-\Delta_{t}^{a} d P_{t}-r\left(V_{t}^{i}-\Delta_{t}^{a} P_{t}\right) d t
$$

Looking at Eqn.(2.4), we use Ito's Lemma to replace the $d V_{t}^{i}$ term, replace the $d S$ term using Eqn.(2.1) and use the Black-Scholes equation (shown in Appendix A) to obtain an incremental profit of

$$
d \Pi_{t}=\frac{1}{2}\left[\left(\sigma^{a}\right)^{2}-\left(\sigma^{i}\right)^{2}\right] P_{t}^{2} \frac{\partial^{2} V^{i}}{\partial P_{t}^{2}} d t+\left(\Delta_{t}^{i}-\Delta_{t}^{a}\right)\left[(\mu-r) P_{t} d t+\sigma P_{t} d B_{t}\right] .
$$


We can go back and rewrite Eqn.(2.4) as

$$
d \Pi_{t}=d V_{t}^{i}-d V_{t}^{a}+r\left(V_{t}^{a}-\Delta_{t}^{a} P_{t}\right)-r\left(V_{t}^{i}-\Delta_{t}^{a} P_{t}\right) d t,
$$

and since we should be perfectly replicating $V_{t}^{a}$ when delta hedging with $\Delta_{t}^{a}$, we have

$$
d V_{t}^{a}-\Delta_{t}^{a} d P_{t}-r\left(V_{t}^{a}-\Delta_{t}^{a} P_{t}\right) d t=0 .
$$

Hence,

$$
d \Pi_{t}=e^{r t} d\left(e^{-r t}\left[V_{t}^{i}-V_{t}^{a}\right]\right) .
$$

If we integrate the incremental profit's present value from time $t_{0}$ to $T$ to get the total profit we get

$$
\int_{t_{0}}^{T} e^{-r\left(t-t_{0}\right)} d \Pi_{t}=e^{r t_{0}} \int_{t_{0}}^{T} d\left(e^{-r t}\left[V_{t}^{i}-V_{t}^{a}\right]\right)=V_{t_{0}}^{a}-V_{t_{0}}^{i}
$$

We described above a situation where an investor profits from buying a European call option when $\sigma^{a}>\sigma^{i}$, but an investor could profit when $\sigma^{a}<\sigma^{i}$ by selling a European call option and delta hedging. In that case, the present value of the total profit would be $V_{t_{0}}^{i}-V_{t_{0}}^{a}$. The absolute values in Theorem 1 are to represent both cases. The important results here are that the profit after each time step contains $d B_{t}$ terms, so it is random and can result in losses on shorter timescales, while the total profit is deterministic and given by the initial difference in the prices of the option using the actual volatility and the implied volatility. A few trajectories of simulated profit curves are shown on the left hand side of Figure 2.1. The profits represent the cumulative additions of the present value of the incremental profits, 
as given on the right hand side of Eqn.(2.4). We can see that the total profits in the simulations are not identical, as predicted in Theorem 1, due to the effects of discrete hedging.

\subsection{Delta Hedging with $\sigma^{i}$}

If the investor were to follow the same strategy as in Section 2.2, but instead hedge with $\Delta_{t}^{i}$, we will see that the incremental mark-to-market profit is guaranteed to be positive, but the total profit is now a random variable.

Theorem 2. When $\sigma^{a} \neq \sigma^{i}$ and the investor delta hedges the sale or purchase of the option with $\sigma^{i}$ to take advantage of volatility arbitrage, the incremental profit between time $t$ and $t+d t, d \Pi_{t}$, is given by

$$
d \Pi_{t}=\frac{1}{2}\left|\left(\sigma^{a}\right)^{2}-\left(\sigma^{i}\right)^{2}\right| P_{t}^{2} \frac{\partial^{2} V_{t}^{i}}{\partial P_{t}^{2}} d t .
$$

Proof. The investor's incremental profit will be given by

$$
d \Pi_{t}=d V_{t}^{i}-\Delta_{t}^{i} d P_{t}-r\left(V_{t}^{i}-\Delta_{t}^{i} P_{t}\right) d t
$$

Using Ito's Lemma to replace the $d V_{t}^{i}$ term gives

$$
d \Pi_{t}=\frac{1}{2}\left[\left(\sigma^{a}\right)^{2}-\left(\sigma^{i}\right)^{2}\right] P_{t}^{2} \frac{\partial^{2} V_{t}^{i}}{\partial P_{t}^{2}} d t .
$$

The absolute values are present in Theorem 2 to acknowledge the situation opposite to that we just described, where $\sigma^{i}>\sigma^{a}$ and the investor is selling the option and 
buying stock. Integrating the present value of the profits from time $t_{0}$ to $T$ gives the total profit

$$
\int_{t_{0}}^{T} e^{-r\left(t-t_{0}\right)} d \Pi_{t}=\frac{1}{2}\left[\left(\sigma^{a}\right)^{2}-\left(\sigma^{i}\right)^{2}\right] \int_{t_{0}}^{T} e^{-r\left(t-t_{0}\right)} P_{t}^{2} \frac{\partial^{2} V_{t}^{i}}{\partial P_{t}^{2}} d t
$$

Now, the profit from one time step to the next is deterministic $\left(d P_{t}\right.$ terms have cancelled) but the total profit made between $t_{0}$ and $T$ is now path dependent. We can see that to maximize this profit the investor would hope for the stock price to end up near the option strike price, as this would result in the largest value of $\frac{\partial^{2} V_{t}^{i}}{\partial P_{t}^{2}}$ (Ahmad and Wilmott, 2005). There is a reassuring simplicity to this situation since as long as the investor's estimate of the actual volatility is on the correct side of the implied volatility, he or she is guaranteed a profit over each time step. Ahmad and Wilmott (2005) also derive the distribution of the final profit mean and standard deviation in this situation (some results in Appendix A). The right hand side of Figure 2.1 shows a few trajectories of the profit when hedging using this strategy. The profits here are calculated as the cumulative sum of the present values of the incremental profits, as described on the right hand side of Eqn.(2.5). We can see that the investor never has to worry about the possibility of losses during the life of the option. 

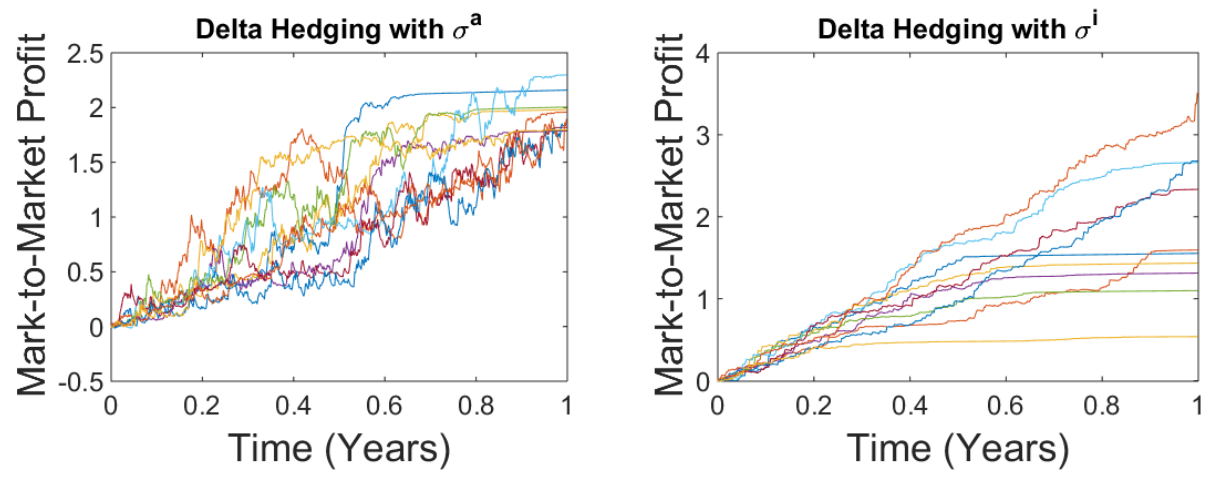

Figure 2.1: The Profit Curves when delta hedging a European call option with Left: $\sigma^{a}$ Right: $\quad \sigma^{i}$. Parameters used are $S_{0}=50, \mu=0, \sigma^{a}=0.3, \sigma^{i}=0.2$, $K=50, r=0.05$ and $q=0$. These results are generated by simulations of the underlying stock where the investor rebalances 500 times over the life of the option.

\subsection{Delta Hedging with $\sigma^{h}$ and Extensions}

Of course, it is possible to delta hedge using a volatility that is neither $\sigma^{a}$ nor $\sigma^{i}$. Using a different volatility $\left(\sigma^{h}\right)$ to hedge can allow the investor to balance the pros and cons of the two hedging strategies (Ahmad and Wilmott, 2005). However, in general, the further your choice of hedging volatility is from $\sigma^{a}$ the larger the standard deviation of the total profit. Hence, the further your hedging volatility is from $\sigma^{a}$, the more likely the investor is to lose money. Ahmad and Wilmott (2005) show that an investor can still expect to profit from the volatility arbitrage opportunity in Section 2.2 with a wide range of hedging volatilities. For this reason, we can label the Black-Scholes delta hedging strategy as robust to misspecification 
of its only unobservable parameter. A more sophisticated approach is taken by Jonsson et. al (2015), who derive formulas equivalent to Theorem 1 and 2, but in a much more general framework that allows for non-constant values for all stock parameters, a non-constant $\sigma^{i}$ and even jumps. 


\section{Chapter 3}

\section{HEDGING ILLIQUID CLAIMS AND VOLATILITY ARBITRAGE}

\subsection{Introduction}

In the idealized Black-Scholes world of Ahmad and Wilmott (2005), it is possible to create a dynamic hedging strategy, using the underlying stock and a risk free bond, that perfectly replicates the payoffs of any European calls and puts with expiration time T. However, if for some reason the buyer or seller of an option is unable or unwilling to trade with the underlying, but does so instead with a second, correlated stock, it will be impossible to achieve perfect replication. This scenario is referred to as an incomplete market. There are many situations where it may not be possible for an investor to hedge with the underlying directly. For example, it can be difficult, perhaps as a result of transaction costs, to hedge a basket option using its components stocks. Davis (2000) discusses his time working on the trading floor in Tokyo, and mentions that traders had poor intuition when hedging with correlated assets. He explains that when hedging a book of equity options, transaction costs involved in trading the underlying make it much cheaper to instead hedge with index futures. Davis (2000) reports that the traders were happy to use the index as a proxy asset to hedge but often had little idea of the risks involved. Another example is when the claim is on an asset with no liquid market. Davis (2000) proposes hedging 
a call option on Dubai oil with forward contracts on Brent crude oil. A third example is executive stock options, where the owner of an option is prohibited by law from trading the underlying stock. In 1998, stock options accounted for $40 \%$ of American CEO's pay, and the practice of stock options compensation for CEO's was rising worldwide as of 2002 (Henderson, 2001b). However, recently there has been a broad trend away from stock option compensation for CEOs, as some investors fear that they may incentivize short-term or risky actions on the part of the CEO (McFarland, 2015). However, according to McFarland (2015), they are still an important component of many CEO compensation packages.

\subsection{Setting}

Ahmad and Wilmott (2005) study methods of profiting from volatility arbitrage in a Black-Scholes framework, where the volatility is the only unobservable parameter influencing the value of an option. How would an investor profit from volatility arbitrage in an incomplete market? Before we can answer that we must first establish how to price options in this incomplete market. The financial setup here involves an investor holding a certain amount of claims on some untraded asset, while trading with a second correlated stock. We call $\left(P_{t}\right)_{0 \leqslant t \leqslant T}$ the price of the traded stock and $\left(S_{t}\right)_{0 \leqslant t \leqslant T}$ the price of the non-traded stock and we take both to be observable at all 
times. Both prices follow log-normal diffusions:

$$
\begin{aligned}
& \frac{d P_{t}}{P_{t}}=\mu d t+\sigma d B_{t}^{(1)} \\
& \frac{d S_{t}}{S_{t}}=v d t+\eta \rho d B_{t}^{(1)}+\eta \sqrt{1-\rho^{2}} d B_{t}^{(2)},
\end{aligned}
$$

where $\mu$ and $v$ are constants representing the expected returns for the traded and untraded stock respectively, and $\sigma$ and $\eta$ are constants representing the volatilities of the traded and untraded stocks. $\left(B_{t}^{(1)}, B_{t}^{(2)}\right)_{0 \leqslant t \leqslant T}$ are independent Brownian motions and $\rho$ is the correlation between the two stocks, with $-1 \leqslant \rho \leqslant 1$. The investor will be hedging a bundle composed of some number, $\lambda$, of identical European options, each with non-negative payoff function $h$ and expiration time $T$. We work with the filtered probability space $\left(\Omega, \mathcal{F}, \mathcal{F}_{t}, \mathcal{P}\right)$, where $\left(\mathcal{F}_{t}\right)_{0 \leqslant t \leqslant T}$ is generated by $\left(B_{t}^{(1)}, B_{t}^{(2)}\right)$. For mathematical convenience we will sometimes work with $Y_{t}=\ln \left(S_{t}\right)$

The investor has the choice of investing their wealth at time $t,\left(W_{t}\right)_{0 \leqslant t \leqslant T}$, in some combination of an amount in a risk free bond, $\left(M_{t}\right)_{0 \leqslant t \leqslant T}$, and an amount in the traded stock, represented by the adapted process $\left(\pi_{t}\right)_{0 \leqslant t \leqslant T}$. The investor's wealth will then evolve according to

$$
\begin{aligned}
d W_{t} & =\pi_{t} \frac{d P_{t}}{P_{t}}+\left(W_{t}-\pi_{t}\right) r d t \\
& =r W_{t} d t+\pi_{t}\left[(\mu-r) d t+\sigma d B_{t}^{(1)}\right]
\end{aligned}
$$

The amount invested in a risk free bond at time $t$ is given by $M_{t}=W_{t}-\pi_{t}$. We require that $\int_{0}^{T} \pi_{t}^{2} d t<\infty$ a.s. We will also require a class of admissible hedging 
strategies to prevent doubling strategies. We do this in order to obtain a meaningful optimization later in Eqn.(3.2) (Davis, 2000). To accomplish this, we borrow the following definitions (see page 7 of Davis (2000)): We call $\mathcal{L}_{0}$ the set of trading strategies. We define:

$$
\mathcal{L}_{b}=\left\{\pi \in \mathcal{L}_{0}: W_{t} \geq z_{\pi} \text { a.s. } \forall t \in[0, T], \text { for some } z_{\pi} \in \mathbb{R}\right\}
$$

and

$$
\mathcal{U}=\left\{U\left(W_{T}+h\left(Y_{T}\right)\right): \pi \in \mathcal{L}_{b}\right\}^{c},
$$

where $\{\ldots\}^{c}$ represents the closure in $L_{1}\left(\Omega, \mathcal{F}_{T}, \mathcal{P}\right)$. We then define the set of admissible strategies to be $\mathcal{L}$ where

$$
\mathcal{L}=\left\{\pi_{t} \in \mathcal{L}_{0}: U\left(W_{T}+h\left(Y_{T}\right)\right) \in \mathcal{U}\right\}
$$

Note that $U$ is the investor's exponential utility function and $\mathrm{h}$ is the option's payoff function, which we assume to be bounded from below.

\subsection{Two Pricing Approaches in Incomplete Markets}

In this incomplete market, we no longer have the Black-Scholes pricing formula to unambiguously provide the price of options. Hence, we must make a pricing decision. The first possibility we will consider requires us to solve the investor's optimization problem given by

$$
J^{\lambda}(t, w, y)=\sup _{\pi \in \mathcal{L}}\left(-\frac{1}{\gamma} \mathbb{E}_{w, y, t}\left[\exp \left(-\gamma\left(W_{T}+\lambda h\left(e^{Y_{T}}\right)\right)\right)\right]\right)
$$


where $E_{t, w, y}$ represents $\mathcal{P}$-expectation conditional on $W_{t}=w, Y_{t}=y$. The superscript $(\ldots)^{\lambda}$ refers to the number of identical option payoffs to occur at time $T$. Note that in Eqn.(3.2), the investor is optimizing the expectation of an exponential utility function with risk preference constant $\gamma>0$, making the investor risk averse. To price a bundle of $\lambda$ identical options, we must consider two special cases of the above optimization. For the first we consider only the optimal allocation of resources between the traded asset and the risk free bond. The second is the same optimization when the investor also has an option position composed of $\lambda$ options (Henderson, 2002).

Definition 1. The utility indifference price of a bundle of $\lambda$ options, $\tilde{V}(t, y ; \eta, \sigma v, \mu, v, \rho ; \gamma, \lambda, T)$, is found by solving

$$
J^{0}(t, w+\tilde{V}, y ;)=J^{\lambda}(t, w, y)
$$

for $\tilde{V}$.

Essentially, the utility indifference price is the amount of money which leaves an investor indifferent between a portfolio containing the options and one without them but with the addition of $\tilde{V}$ to his or her starting wealth.

The second pricing approach is from Forsyth et al. (2005), who derive their method by creating a portfolio that consists of a bundle of identical European options and some amount of the traded stock, and then hedging in such a way as to minimize the variance in the change of the portfolio's value after a time increment. This is 
explained more thoroughly in Section 3.5. They then require the portfolio to be mean self-financing by enforcing $\mathbb{E}[d \Pi]=0$ and derive the pricing equation

$$
\frac{\partial \hat{V}_{t}}{\partial t}+S_{t} \frac{\partial \hat{V}_{t}}{\partial S_{t}}\left(v-\frac{(\mu-r) \eta \rho}{\sigma}\right)+\frac{\eta^{2} S_{t}^{2}}{2} \frac{\partial^{2} \hat{V}_{t}}{\partial S_{t}^{2}}-r \hat{V}_{t}=0
$$

with boundary conditions:

$$
\begin{aligned}
& \hat{V}\left(T, S_{T}\right)=h\left(S_{T}\right), \\
& \hat{V}(t, 0)=0, \\
& \hat{V}\left(t, S_{t}\right) \rightarrow S_{t} \text { as } S_{t} \rightarrow \infty .
\end{aligned}
$$

We can see immediately that this is the same equation that describes the change in the Black-Scholes price of a European option with a underlying stock that pays continuous dividends of yield $q=\frac{(\mu-r) \eta \rho}{\sigma}-v+r$ (Forsyth et al., 2005). Hence, we have a definition for our second option pricing method.

Definition 2. The minimum local variance price for a bundle of $\lambda$ identical options, $\hat{V}(t, y ; \eta, \sigma, \mu, v, \rho ; \lambda, T)$, is given by:

$$
\hat{V}(t, y)=\lambda\left[\operatorname{BS}\left(t, y ; \frac{(\mu-r) \eta \rho}{\sigma}-v+r, \eta\right)\right]
$$

where $B S(t, y ; q, \eta)$ is the Black-Scholes price of a European option with an underlying that pays out a continuous dividend yield of $q$ and has volatility $\eta$. 


\subsection{Hedging Strategy 1 - Maximizing Utility of Terminal Wealth}

The first hedging strategy will achieve the supremum given in Eqn.(3.2). It has been shown that the optimization is only meaningful when $\lambda h\left(\mathrm{e}^{Y_{t}}\right)$ is bounded below (Henderson, 2002). This eliminates short positions in call options.

Theorem 3. The dynamic strategy that achieves the supremum in Eqn.(3.2) is to invest in the traded asset, at time $t \in[0, T]$, the amount

$$
\tilde{\pi}(t, y)=\mathrm{e}^{-r(T-t)} \frac{(\mu-r)}{\gamma \sigma^{2}}+\mathrm{e}^{-r(T-t)} \frac{\eta \rho}{\gamma \sigma} \frac{\partial(\ln g)}{\partial y}
$$

where $g$ is as it appears in Eqn.(3.4).

Proof. See Appendix B.

The function $g$ is given by

$$
g(\tau, y)=e^{\frac{-(\mu-r)^{2} \tau}{2 \sigma^{2}}}\left[\int_{-\infty}^{\infty} G\left(0, y+\left(\delta-\frac{1}{2} \eta^{2}\right) \tau+z\right) \frac{e^{-\frac{z^{2}}{2 \eta^{2} \tau}}}{\eta \sqrt{2 \pi \tau}} d z\right]^{1 /\left(1-\rho^{2}\right)}
$$

where

$$
G(0, y)=\exp \left(-\lambda \gamma\left(1-\rho^{2}\right) h\left(e^{y}\right)\right)
$$

and

$$
\delta=v-\frac{\eta \rho(\mu-r)}{\sigma}, \quad \tau=T-t
$$


The first term on the right hand side of the hedging strategy in Theorem 3 corresponds to the solution when optimizing the allocation of wealth between a single traded asset and a risk free bond when the investor has an exponential utility function with risk preference constant $\gamma$. Thus, it is the investment strategy that would achieve the supremum of Eqn.(3.2) with $\lambda=0$. Here, we follow the lead of Monoyios (2004) and consider the right term to be our maximal utility hedge. It can be shown that the maximal utility hedge can also be written as

$$
\tilde{\pi}(t, y)=\frac{\rho \eta S_{t}}{\sigma} \frac{\partial \tilde{V}_{t}}{\partial S_{t}}
$$

The details of this proof can also be found in Appendix B. It is worth noting that the Equation in Theorem 3 is valid only when $-1<\rho<1$. When $|\rho|=1$, it is obvious from the alternative formulation that the maximal utility strategy is equivalent to the adjusted Black-Scholes described below.

\subsection{Hedging Strategy 2 - Minimizing Portfolio Variance}

Here we will seek a hedge which could be more appealing to an investor who is more interested in managing the local risk of their portfolio than in maximizing their terminal utility. The goal of this strategy will be to minimize the variance in the incremental profit and loss of the investor. A key difference from the previous strategy is that it does not require the investor to quantify their risk preferences. 
Theorem 4. The hedging strategy that minimizes the variance of the investor's incremental profit is to invest in the traded asset at time $t \in[0, T]$, the amount:

$$
\hat{\pi}(t, y)=-\left(\frac{\eta S_{t} \rho}{\sigma}\right) \frac{\partial \hat{V}_{t}}{\partial S_{t}}=-\left(\frac{\eta \rho}{\sigma}\right) \frac{\partial \hat{V}_{t}}{\partial y}
$$

where $\hat{V}$ is the option pricing formula of Definition 2.

Proof. This strategy can be derived from considering an investment scenario in the setting of Section 3.2. We consider an investor with a long European call position, invests $\pi_{t}$ in a tradeable stock, with some correlation with the option underlying, and invests $M_{t}$ in a risk free bond. The amount in the risk free bond is such that

$$
M_{t}+\hat{V}_{t}+\pi_{t}=0
$$

So, money is constantly being injected into or removed from the portfolio. These are considered to be the investor's incremental profits and losses. Note that we calculate profit using the option pricing formula for $\hat{V}$ of Definition 2. The incremental change in portfolio value, before rebalancing, is given by

$$
\begin{gathered}
d \Pi_{t}=\left[\frac{\partial \hat{V}_{t}}{\partial t}+v S_{t} \frac{\partial \hat{V}_{t}}{\partial S_{t}}+\frac{\eta^{2} S_{t}^{2}}{2} \frac{\partial^{2} \hat{V}_{t}}{\partial S_{t}^{2}}\right] d t+\eta S \frac{\partial \hat{V}_{t}}{\partial S_{t}}\left[\rho d B_{t}^{(1)}\right. \\
\left.+\sqrt{\left(1-\rho^{2}\right)} d B_{t}^{(2)}\right]+\pi_{t}\left(\mu d t+\sigma d B_{t}^{(1)}\right)+\left(-\hat{V}_{t}-\pi_{t}\right) r d t .
\end{gathered}
$$

Therefore,

$$
\operatorname{Var}\left[d \Pi_{t}\right]=\mathbb{E}\left[\left(\eta S \frac{\partial \hat{V}_{t}}{\partial S_{t}}\left[\rho d B_{t}^{(1)}+\sqrt{\left(1-\rho^{2}\right)} d B_{t}^{(2)}\right]+\pi_{t} \sigma d B_{t}^{(1)}\right)^{2}\right] .
$$

Taking the derivative of the expression for the variance with respect to $\pi_{t}$ and setting it equal to 0 allows us to find the amount invested into the tradeable stock that 
minimizes the variance of the profit. The result is Theorem 4 .

\subsection{Hedging Strategy 3 - Adjusted Black-Scholes}

The third strategy will be referred to throughout as the adjusted Black-Scholes strategy. We will consider an investor following this strategy to be "naive" (Monoyios, 2005), since it can be derived by assuming the traded and untraded stocks Brownian motions to be perfectly correlated. The purpose of including this hedging strategy in our analysis is to contrast it with the two more sophisticated dynamic hedging strategies. When $\rho=1$, the market is complete, and the price of the options must be the Black-Scholes price. Consider an investor who owns a portfolio composed of an option, with value $V_{t}$, and some amount, $\pi_{t}$, in the tradeable asset. After a single time step, the change in the portfolio value will be

$$
\begin{array}{r}
d \Pi=\left[\frac{\partial V_{t}}{\partial t}+v S \frac{\partial V_{t}}{\partial S_{t}}+\frac{\eta^{2} S_{t}^{2}}{2} \frac{\partial^{2} V_{t}}{\partial S_{t}^{2}}\right] d t+\eta S_{t} \frac{\partial V_{t}}{\partial S_{t}} d B_{t}^{(1)} \\
+\pi_{t}\left(\mu d t+\sigma d B_{t}^{(1)}\right),
\end{array}
$$

So, if the investor invests

$$
\pi_{t}=-\left(\frac{\eta S_{t}}{\sigma}\right) \frac{\partial V_{t}}{\partial S_{t}}
$$


every $d B^{(1)}$ term cancels out, eliminating risk from the portfolio. Hence, this portfolio must grow at the risk-free rate:

$$
r \Pi_{t} d t=r\left[V_{t}-\left(\frac{\eta S_{t}}{\sigma}\right) \frac{\partial V_{t}}{\partial S_{t}}\right] d t=\left[\frac{\partial \hat{V}_{t}}{\partial t}+\frac{\eta^{2} S_{t}^{2}}{2} \frac{\partial^{2} \hat{V}_{t}}{\partial S_{t}^{2}}+v S \frac{\partial \hat{V}_{t}}{\partial S_{t}}-\frac{\eta \mu S_{t}}{\sigma} \frac{\partial \hat{V}_{t}}{\partial S_{t}}\right] d t
$$

We divide both sides by $\mathrm{dt}$, rearrange and enforcing the no arbitrage condition

$$
v=\left(\frac{\mu-r}{\sigma}\right) \eta+r
$$

which results from requiring that a risk-free portfolio created with the two stocks described in Section 3.2, grow at the risk-free rate. Eqn.(3.5) then becomes:

$$
\frac{\partial \hat{V}_{t}}{\partial t}+\frac{\eta^{2} S_{t}^{2}}{2} \frac{\partial^{2} \hat{V}_{t}}{\partial S_{t}^{2}}+r S_{t} \frac{\partial \hat{V}_{t}}{\partial S_{t}}-r \hat{V}_{t}=0
$$

This is the standard Black-Scholes option pricing equation.

Definition 3. An investor who believes that $\rho=1$ will hedge by investing in the traded asset, at time $t \in[0, T]$, the amount:

$$
\pi_{t}^{\mathrm{BS}}(t, y)=-\left(\frac{\eta}{\sigma}\right) \frac{\partial[\mathrm{BS}(t, y ; 0, \eta)]}{\partial y} .
$$

We can see that the "naive" investor does not require estimates of $\mu, v$ or $\rho$ and does not need to specify a value for $\gamma$.

\subsection{Volatility Arbitrage in an Incomplete Market}

One of the obvious differences in this incomplete market setting, as compared to the Black-Scholes world of Ahmad and Wilmott (2005), is that there are now possibly 
six parameters that are unobservable and affect option values. These are $\sigma, \eta, \mu, v$, $\rho$ and $\gamma$. Hence, if an investor forecasts that these parameters will have different values than the market predicts, an option can be identified as being mispriced. Below, we will study the volatility arbitrage resulting from an investor possessing a more accurate estimate of the future volatility of the untraded stock, $\eta^{a}$, than the market. A significant complication in this setting is the investor must somehow determine the market's estimate for the untraded stock volatility, $\eta^{i}$, from the market price of the option. In the Black-Scholes framework this is simple, as the formula can be easily inverted to find the implied volatility. In this incomplete setting, an investor must first take certain values as market estimates for the other parameters before inverting either the utility difference price formula or the minimal variance price formula to find $\eta^{i}$. Throughout, we will assume that the investor has determined $\eta^{i}$ by inverting the minimal variance price formula, from Definition 2 , using the current market price for the option bundle. A second complication arises from the fact that the option price is not necessarily increasing with respect to $\eta$. Hence, a larger value for $\eta$ may in fact lead to a lower price for the option (Henderson and Hobson, 2002). For the minimal variance pricing approach, the reason for this is easy to understand. In Section 3.3, we showed that the price is given by the Black-Scholes option price with continuous dividend yield $q=\frac{(\mu-r) \eta \rho}{\sigma}-v+r$. While a larger $\eta$ will, in one sense, act to increase the option value, if $(\mu-r) \rho>0$, then a larger $\eta$ will result in a larger continuous dividend yield, which acts to reduce the value of a 
call option. If this second effect is larger, the net change of a larger value for $\eta$ will be to decrease the call option's value. The first two hedging strategies were chosen from the literature because they can be viewed as incomplete market analogs to the hedging strategies of Ahmad and Wilmott (2005). The maximal utility strategy is similar to hedging with the actual volatility, since it concerns maximizing with respect to the expiration time, and the minimal variance strategy is analogous to hedging with the implied volatility since its purpose is to minimize local portfolio properties. The adjusted Black-Scholes strategy was chosen to determine what results a "naive" investor would have with a much simpler strategy. Below, we perform an analysis similar to Ahmad and Wilmott (2005), in that we compare the mark-to-market incremental and total profits. We also experiment with different values of the hedging parameters, to determine how robust each strategy is to misspecification. We study both the effect this has on the investor's profit distributions as well as on the expected value of their terminal wealth.

\subsection{Comparing the Hedging Strategies - Comparing Incremental Profits}

Justifying the use of a hedging strategy based on the distribution of its incremental profits can be done in a scenario where the buyer or seller of options is concerned about risk and wants to "limit the damage" and close their position early. It can also be justified if there is a risk management department that is keeping track of the mark-to-market profits and would be concerned about short-term losses (Ahmad 
and Wilmott, 2005). We begin this section by deriving a result in the incomplete market setting that is analogous to Theorem 2 .

Theorem 5. When $\eta^{a} \neq \eta^{i}$ and the investor hedges the purchase or sale of an option on an illiquid underlying according to the strategy in Theorem 4 (but using $\left.\hat{V}_{t}^{i}\right)$ with the traded asset, the incremental profit is given by

$$
d \Pi_{t}=\left(\frac{S_{t}^{2}}{2} \frac{\partial^{2} \hat{V}_{t}^{i}}{\partial S_{t}^{2}}\right)\left|\left(\eta^{a}\right)^{2}-\left(\eta^{i}\right)^{2}\right| d t \pm \eta S \frac{\partial V_{t}^{i}}{\partial S_{t}}\left(\sqrt{1-\rho^{2}}\right) d B_{t}^{(2)}
$$

Note that the second term is positive when the investor's profitable strategy is to purchase the option and negative when it is to sell the option.

Proof. We consider an investor who has somehow inverted the pricing equation of Definition 2 to obtain $\sigma^{i}=0.1$. The investor, however, believes that the actual volatility of the untraded asset will be $\sigma^{a}=0.2$. Note that the proof for when $\sigma^{i}>\sigma^{a}$ is nearly identical. This means that the investor can attempt to profit from volatility arbitrage by buying the bundle of options and hedging. If the investor acts as in the proof for Theorem 4, but we instead consider the mark-to-market profit (meaning we value the option position using $\eta=\eta^{i}$ in Definition 2), we find the incremental profit to be

$$
\begin{array}{r}
d \Pi_{t}=\left[\frac{\partial \hat{V}_{t}^{i}}{\partial t}+v S_{t} \frac{\partial \hat{V}_{t}^{i}}{\partial S_{t}}+\frac{\eta^{2} S_{t}^{2}}{2} \frac{\partial^{2} \hat{V}_{t}^{i}}{\partial S_{t}^{2}}\right] d t+\eta S \frac{\partial \hat{V}_{t}^{i}}{\partial S_{t}}\left[\rho d B_{t}^{(1)}\right. \\
\left.+\sqrt{\left(1-\rho^{2}\right)} d B_{t}^{(2)}\right]+\pi_{t}\left(\mu d t+\sigma d B_{t}^{(1)}\right)+\left(-\hat{V}_{t}^{i}-\pi_{t}\right) r d t
\end{array}
$$


Therefore,

$$
\operatorname{Var}\left[d \Pi_{t}\right]=\mathbb{E}\left[\left(\eta S \frac{\partial \hat{V}_{t}^{i}}{\partial S_{t}}\left[\rho d B_{t}^{(1)}+\sqrt{\left(1-\rho^{2}\right)} d B_{t}^{(2)}\right]+\pi_{t} \sigma d B_{t}^{(1)}\right)^{2}\right] .
$$

Taking the derivative of the right side of the previous equation with respect to $\pi_{t}$ and setting it equal to 0 allows us to find the amount invested into the tradeable stock that minimizes the variance of the mark-to-market profit:

$$
\pi_{t}=-\left(\frac{\eta S_{t} \rho}{\sigma}\right) \frac{\partial \hat{V}_{t}^{i}}{\partial S_{t}}
$$

Substituting this hedge into Eqn.(3.6) gives

$d \Pi_{t}=\left(\frac{\partial \hat{V}_{t}^{i}}{\partial t}+\frac{\eta^{2} S_{t}^{2}}{2} \frac{\partial^{2} \hat{V}_{t}^{i}}{\partial S_{t}^{2}}\right) d t+S_{t} \frac{\partial \hat{V}_{t}^{i}}{\partial S_{t}}\left(v-\frac{(\mu-r) \eta \rho}{\sigma}\right) d t-\hat{V}_{t}^{i} r d t+\eta S_{t} \frac{\partial \hat{V}_{t}^{i}}{\partial S_{t}}\left(\sqrt{1-\rho^{2}}\right) d B_{t}^{(2)}$.

Using Eqn.(3.3), but for $\hat{V}_{t}^{i}$, gives

$$
d \Pi_{t}=\left(\frac{S_{t}^{2}}{2} \frac{\partial^{2} \hat{V}_{t}^{i}}{\partial S_{t}^{2}}\right)\left[\left(\eta^{a}\right)^{2}-\left(\eta^{i}\right)^{2}\right] d t+\eta S_{t} \frac{\partial \hat{V}_{t}^{i}}{\partial S_{t}}\left(\sqrt{1-\rho^{2}}\right) d B_{t}^{(2)}
$$

In the complete market scenario, $\rho \rightarrow 1$ and $v \rightarrow \frac{(\mu-r) \eta \rho}{\sigma}+r$, reduces to the result of Theorem 2. For this reason, we associate the minimal local variance strategy with Ahmad and Wilmott's (2005) strategy of delta hedging with implied volatility. We can see that the incremental profit has a deterministic component and a random component, driven by the Brownian motion increment $\left(d B_{t}^{(2)}\right)$. The properties of the investor's incremental profit will depend heavily on the parameters driving the stock motions, which will change the relative magnitudes of the deterministic and probabilistic components. We can now experiment with some reasonable stock and option parameters to see if the results are comparable to those in Section 2.3. In 
Sections 3.8 to 3.11 , profits are calculated by creating a portfolio at time $t=0$ that is composed of: either a long or short position consisting of a number, $\lambda$, of identical European call or put options, an amount invested in the traded stock, $\pi_{0}$, and an amount in a risk free bond, $M_{0}$, with interest rate $r$, which brings the value of the portfolio to be 0 :

$$
\hat{V}_{0}^{i}+M_{0}+\pi_{0}=0
$$

We can then consider the change in the value of the portfolio to be the investor's profit or loss. Once again, this profit or loss is considered to be mark-to-market as we will calculate the value of the option positions using $\eta^{i}$ (represented using the subscript $\left.(\ldots)^{i}\right)$. We will require the investor's portfolio be self-financing, meaning that the amount invested in the risk free bond evolves according to

$$
M_{t+d t}=M_{t} e^{r d t}-S_{t+d t}\left[\frac{\pi_{t+d t}}{S_{t+d t}}-\frac{\pi_{t}}{S_{t}}\right]
$$

\begin{tabular}{|c|c|c|c|c|c|c|c|c|c|c|c|}
\hline $\boldsymbol{Y}_{\mathbf{0}}$ & $\gamma$ & $\boldsymbol{\eta}^{\boldsymbol{a}}$ & $\boldsymbol{\eta}^{\boldsymbol{i}}$ & $\boldsymbol{\sigma}$ & $\boldsymbol{\mu}$ & $\mathbf{v}$ & $\boldsymbol{\rho}$ & $\mathbf{r}$ & $\mathbf{K}$ & $\mathbf{T}$ (years) & $\boldsymbol{\lambda}$ \\
\hline $\ln (50)$ & 0.0001 & 0.2 & 0.1 & 0.1 & 0.05 & 0.05 & 0.95 & 0.05 & 45 & 1 & 100 \\
\hline
\end{tabular}

Table 3.1: The stock and option parameters used in this section unless otherwise specified. We consider an investor with $\gamma=0.0001$, similar to the investor in Monoyios (2004).

Table 3.1 shows the stock and option parameters used in this section unless otherwise stated. According to Table 3.2, the market has underpriced the bundle 
of European call options, and so an investor can attempt to profit from volatility arbitrage by taking a long position in the calls and hedging until expiration. We begin by looking at the incremental profits in the incredibly unrealistic situation where the untraded stock is nearly perfectly correlated with the traded one ( $\rho=$ 0.9999). The incremental profit results for 10000 trajectory pairs for $Y_{t}$ and $P_{t}$ with 500 uniformly spaced rebalancing times are shown in Tables 3.3 and some of the profit trajectories are plotted in Figure 3.1 (top).

\begin{tabular}{|c|c|c|}
\hline \multicolumn{3}{|c|}{ Call Option Values } \\
\hline $\boldsymbol{\rho}=\mathbf{0 . 9 9 9 9}$ & $\boldsymbol{\eta}=\mathbf{0 . 2}$ & $\boldsymbol{\eta}=\mathbf{0 . 1}$ \\
\hline Utility Indifference & 835.24 & 731.44 \\
\hline Minimum Local Variance & 834.97 & 731.44 \\
\hline $\boldsymbol{\rho}=\mathbf{0 . 9 5}$ & $\boldsymbol{\eta}=\mathbf{0 . 2}$ & $\boldsymbol{\eta}=\mathbf{0 . 1}$ \\
\hline Utility Indifference & 831.11 & 731.44 \\
\hline Minimum Local Variance & 834.97 & 731.44 \\
\hline
\end{tabular}

Table 3.2: The different valuations for the bundle of options resulting from different values of $\rho$ and $\eta$. Here, the larger $\eta$ results in a larger option value, meaning an investor can attempt to profit from a misspecification by buying call options. 


\begin{tabular}{|c|c|}
\hline \multicolumn{2}{|c|}{ Incremental Profit } \\
\hline $\boldsymbol{\rho}=\mathbf{0 . 9 9 9 9}$ & Minimal Variance(Eqn.(3.7)) \\
\hline Profit Mean & 0.21 \\
\hline Profit Std & 0.95 \\
\hline Profit Median & 0.08 \\
\hline
\end{tabular}

Table 3.3: Properties of the incremental profit distribution. The mean is fairly large compared to the standard deviation and thus the investor sees smooth profit curves as in the right hand side of Figure 2.1. The incremental profit is calculated as in Eqn.(3.6). Statistics are generated from 10000 trajectory pair simulations. Note that the properties for a single trajectory pair will be path dependent. 


\begin{tabular}{|c|c|c|c|}
\hline \multicolumn{4}{|c|}{ Incremental Profit } \\
\hline $\boldsymbol{\rho}=\mathbf{0 . 9 5}$ & Maximal Utility & Minimal Variance(Eqn.(3.7)) & Black-Scholes \\
\hline Profit Mean & 0.20 & 0.20 & 0.20 \\
\hline Profit Std & 13.59 & 13.03 & 13.19 \\
\hline Profit Median & 0.02 & 0.03 & 0.03 \\
\hline
\end{tabular}

Table 3.4: Properties of the profit distribution on an incremental basis with a slightly less significant correlation for each of the hedging strategies. The standard deviation is now noticeably larger than the mean, meaning that the noise has made it difficult to justify any particular strategy over the other. These results are from the simulation of 10000 trajectory pairs with 500 uniform rehedging times. Note that we consider the modified Minimal Local Variance Strategy here from Eqn.(3.7) and evaluate the other two with $\eta^{i}$. The incremental profit is calculated as in Eqn.(3.6). Statistics are generated from 10000 trajectory pair simulations. Note that the properties for a single trajectory pair will be path dependent.

We can see that the investor has successfully recreated the smooth mark-tomarket profit curves that Ahmad and Wilmott get when they hedge using implied volatility. However, once we enter even slightly more realistic values for the correlation $\rho$, the smoothness of the trajectories disappears. The reason is that even for $\rho=0.95$, the Brownian component of the incremental profit expression in Theorem 5 dominates the deterministic component. Table 3.4 shows the properties of the 
incremental profit distribution for the three hedging strategies. We can see that the standard deviations of the incremental profits do not differ enough with respect to the means to justify one strategy over the others. In essence, hedging with a correlated stock is much too messy for realistic stock parameters to justify any particular hedging strategy. 

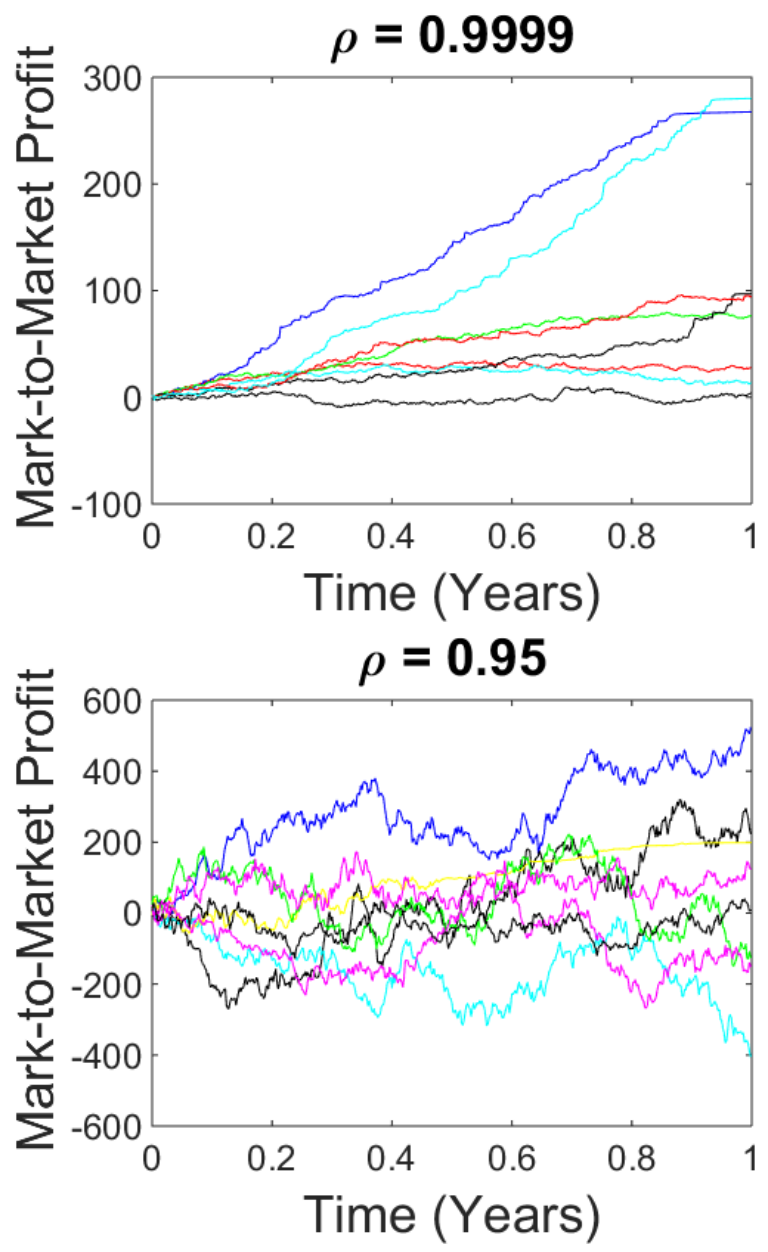

Figure 3.1: Above: Some of the profit trajectories when $\rho=0.9999$ and the stock and option parameters are as in Table 3.1. Below: Profit trajectories when $\rho$ $=0.95$. Even with a very strong correlation the investor loses the smooth profit property. Incremental profits are calculated as in Eqn.(3.7). 


\subsection{Comparing the Hedging Strategies - Comparing Total Profits}

Since there is no obvious way of discerning between the hedging strategies based on the profits they generate over the short-term, we turn our attention to comparing the distributions of the total mark-to-market profits they result in. The investor manages the portfolio of options, stock and money in the risk free bond the same as in Section 3.8. Since we have abandoned comparisons on the basis of incremental profit, when we refer to the minimal variance hedging strategy, we mean the strategy as outlined in Theorem 4. We begin by with a justification for why an investor would hedge with a correlated stock at all, by looking at a situation where the investor leaves the options naked. The parameters used are shown in Table 3.5 (unless otherwise stated) and the market's valuation of the options is compared to the investor's in Table 3.6.

\begin{tabular}{|c|c|c|c|c|c|c|c|c|c|c|c|}
\hline $\boldsymbol{Y}_{\mathbf{0}}$ & $\boldsymbol{\gamma}$ & $\boldsymbol{\eta}^{\boldsymbol{a}}$ & $\boldsymbol{\eta}^{\boldsymbol{i}}$ & $\boldsymbol{\sigma}$ & $\boldsymbol{\mu}$ & $\mathbf{v}$ & $\boldsymbol{\rho}$ & $\mathbf{r}$ & $\mathbf{K}$ & $\mathbf{T}$ (years) & $\boldsymbol{\lambda}$ \\
\hline $\log (50)$ & 0.0001 & 0.2 & 0.1 & 0.1 & 0 & 0 & 0.95 & 0 & 45 & 1 & 100 \\
\hline
\end{tabular}

Table 3.5: Stock and option parameters used in the first part Section 3.9 unless otherwise specified. 


\begin{tabular}{|c|c|c|}
\hline \multicolumn{3}{|c|}{ Call Option Values } \\
\hline $\boldsymbol{\rho}=\mathbf{0 . 9 5}$ & $\boldsymbol{\eta}=\mathbf{0 . 2}$ & $\boldsymbol{\eta}=\mathbf{0 . 1}$ \\
\hline Utility Indifference & 676.25 & 534.64 \\
\hline Minimum Local Variance & 679.46 & 535.62 \\
\hline $\boldsymbol{\rho}=\mathbf{0 . 5 5}$ & $\boldsymbol{\eta}=\mathbf{0 . 2}$ & $\boldsymbol{\eta}=\mathbf{0 . 1}$ \\
\hline Utility Indifference & 657.07 & 528.67 \\
\hline Minimum Local Variance & 679.46 & 535.62 \\
\hline
\end{tabular}

Table 3.6: Different valuations for the bundle of call options resulting from different values of $\rho$ and $\eta$.

The table above shows that the market undervalues the options, and so an investor may profit from purchasing the options and hedging away some of the risk. We can see that simply purchasing the underpriced options and leaving them naked is a profitable strategy on average, but results in a large standard deviation and actually results mostly in losses. We can see in Figures 3.3 and 3.4 that hedging with the correlated stock results in improvements in the profit distribution, most notably in the standard deviation and median. However, even with a very strong correlation, $\rho=0.95$, the standard deviation of the profits is larger than their mean. This seems to be an inevitable reality when hedging with a correlated stock, even when rebalancing fairly frequently. In essence, an investor trying to make money from the market's misspecification of the stock parameters will have to accept significant 
risk. It will likely require a significant misspecification of $\eta$ in order for the investor to be comfortable with the resulting profit distribution. Figure 3.4 shows the profit distributions resulting from the three hedging strategies when $\rho=0.55$. We can see that the maximal utility and minimal local variance hedging strategies result in more right-skewed profit distributions than the adjusted Black-Scholes strategy. The standard deviation of the profits when using the adjusted Black-Scholes hedge is larger than the other two strategies and this results in a significantly larger median profit, although still fairly small in comparison to the profit standard deviation. The drawback is that it results in large losses more often than the other two strategies.

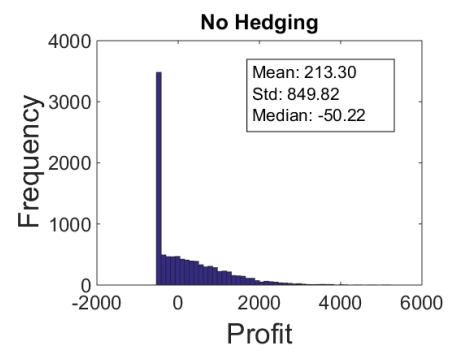

Figure 3.2: The distribution of total profit when long a bundle of European call options, $\rho=0.95$ and the investor does not hedge. The total profit is found by summing the incremental profits calculated using Eqn.(3.6). 

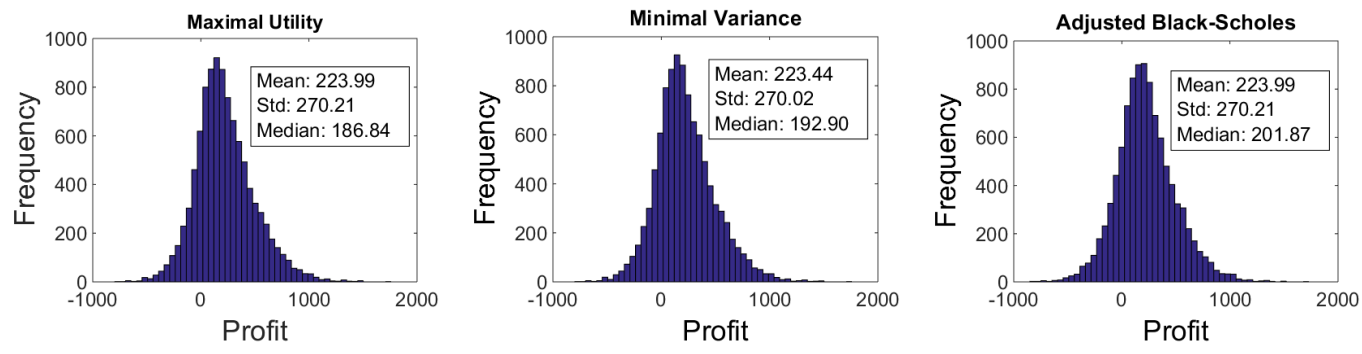

Figure 3.3: The distribution of total profit when long a bundle of European call options, $\rho=0.95$ and the investor hedges using strategy Left: Maximal Utility, Center: Minimal Variance, Right: Adjusted Black-Scholes. The total profit is found by summing the incremental profits calculated using Eqn.(3.6).
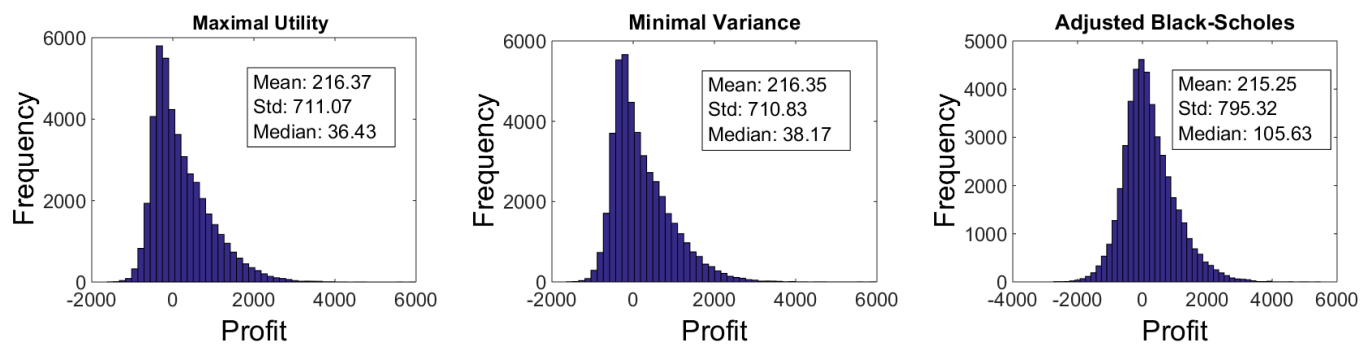

Figure 3.4: The distribution of total profit when long a bundle of European call options, $\rho=0.55$ and we hedge using strategy Left: Maximal Utility, Center: Minimal Variance, Right: Adjusted Black-Scholes. The total profit is found by summing the incremental profits calculated using Eqn.(3.6).

We can perform the same analysis when an investor is shorting European options (if $\eta^{i}>\eta^{a}$ : Here we use $\eta^{i}=0.2$ and $\left.\eta^{a}=0.1\right)$. Repeating the same analysis as before, with $\rho=0.55$, results in the profit distribution shown in Figure 3.5. Remember that the maximal utility hedge as defined does not exist when short European calls. We 
see that the minimal variance strategy results in a more left-skewed distribution than the adjusted Black-Scholes strategy. Hence, the median profit is now largest with the minimal local variance strategy. Once again, as we would expect, the standard deviation of the profit is smallest when using the minimal variance hedging strategy.
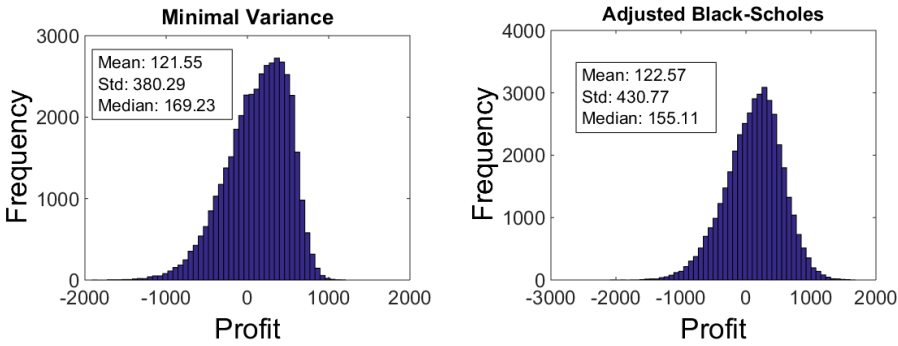

Figure 3.5: Distribution of the total profit when short a bundle of 100 European call options and using the hedging strategy: Left: Minimal Variance. Right: Adjusted Black-Scholes. The total profit is found by summing the incremental profits calculated using Eqn.(3.6).

If we want to include the maximal utility hedging strategy when an investor shorts options, we can look at an investor being short a bundle of European puts. Table 3.7 shows the stock and option parameters used and Table 3.8 shows the difference between the investor and the market's valuation of the bundle. Figure 3.6 shows the profit distributions resulting from each strategy. Note that we also include the maximal utility results when the investor takes a larger value for $\gamma=0.001$. We can see that the larger value for $\gamma$ reduces the skew of the profit distribution and thus results in a lower median profit. Previous work comparing the maximal utility 
strategy with the adjusted Black-Scholes strategy (Monoyios, 2004) took the larger median profit of the utility based strategy as the deciding factor in determining it a superior strategy. It is worth noting that when the investor chooses to buy the option to profit from volatility arbitrage, the skew reverses. We also note that simply comparing the profit distributions has no input from the investor's risk preferences. These will be crucial when making a decision in an environment where there is so much uncertainty as to the final result. Figure 3.7 shows the evolution of the amount each strategy demands in the traded stock. Results such as these can be relevant when considering an investor who must pay transaction costs to trade, and may have incentive to minimize change in the amount of stock held throughout the lifetime of the option position.

\begin{tabular}{|c|c|c|c|c|c|c|c|c|c|c|c|}
\hline $\boldsymbol{Y}_{\mathbf{0}}$ & $\boldsymbol{\gamma}$ & $\boldsymbol{\eta}^{\boldsymbol{a}}$ & $\boldsymbol{\eta}^{\boldsymbol{i}}$ & $\boldsymbol{\sigma}$ & $\boldsymbol{\mu}$ & $\mathbf{v}$ & $\boldsymbol{\rho}$ & $\mathbf{r}$ & $\mathbf{K}$ & $\mathbf{T}$ (years) & $\boldsymbol{\lambda}$ \\
\hline $\ln (50)$ & 0.0001 & 0.1 & 0.2 & 0.1 & 0.05 & 0.05 & 0.55 & 0.05 & 50 & 1 & -500 \\
\hline
\end{tabular}

Table 3.7: The stock and option parameters used in the rest of this section unless otherwise specified. 


\begin{tabular}{|c|c|c|}
\hline \multicolumn{3}{|c|}{ Call Option Values } \\
\hline $\boldsymbol{\rho}=\mathbf{0 . 5 5}$ & $\boldsymbol{\eta}=\mathbf{0 . 2}$ & $\boldsymbol{\eta}=\mathbf{0 . 1}$ \\
\hline Utility Indifference & 1580.60 & 516.95 \\
\hline Local Minimum Variance & 1393.40 & 481.98 \\
\hline
\end{tabular}

Table 3.8: The different valuations for the bundle of puts resulting from different values of $\eta$. Here, the larger $\eta$ results in a larger option value, meaning can investor can profit from a misspecification by selling call options. 

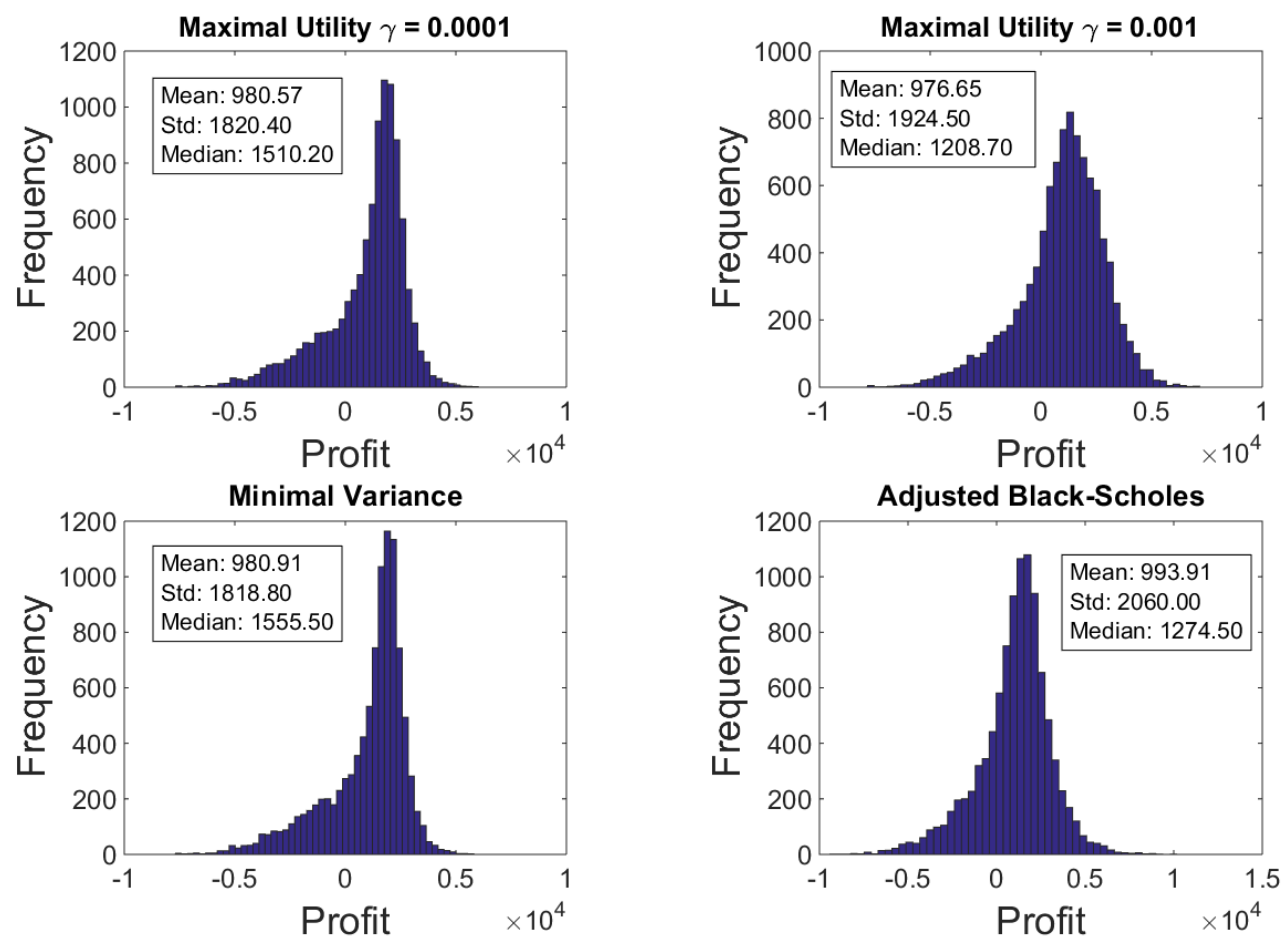

Figure 3.6: The distribution of total profit when short a bundle of European puts, $\rho=0.55$ and we hedge using strategy Top Left: Maximal Utility $\gamma=0.0001$, Top Right: Maximal Utility $\gamma=0.001$, Bottom Left: Minimal Variance, Bottom Right: Adjusted Black-Scholes. The total profit is found by summing the incremental profits calculated using Eqn.(3.6). 


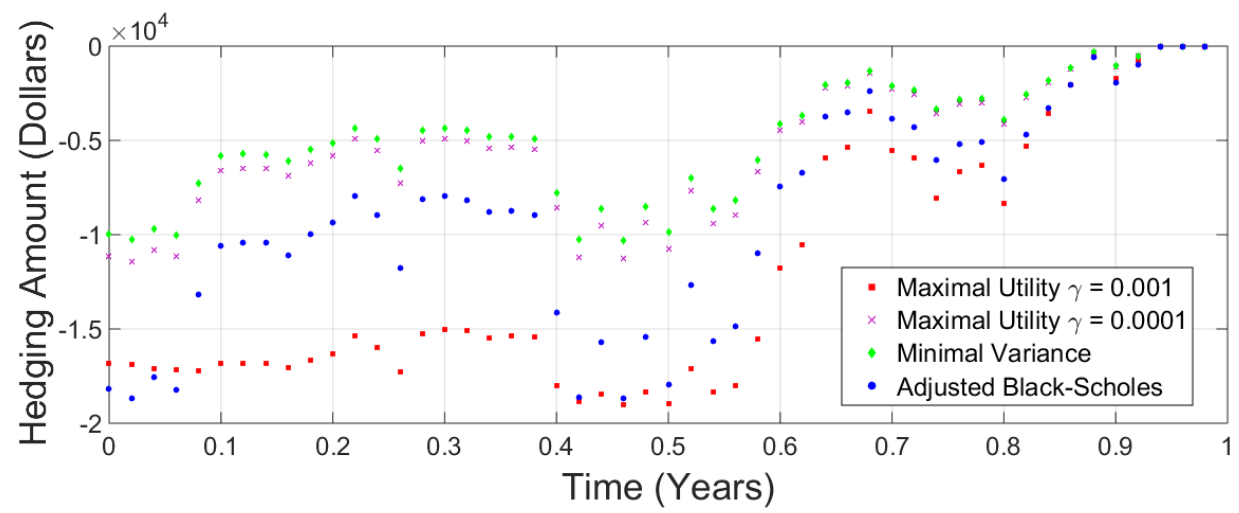

Figure 3.7: The amount of money invested in the traded stock by each hedging strategy when the investor has sold 500 European call options.. The similarity between the minimal variance strategy and the maximal utility strategy $(\gamma=0.0001)$ explain why the profit results are so similar.

\subsection{Comparing the Hedging Strategies - Robustness to Parameter Mis- specification - Profit Distribution}

When evaluating hedging strategies it is also important to consider their robustness to misspecification of stock parameters. In the Black-Scholes world, hedging requires the input of only one unobserved parameter: the volatility. Ahmad and Wilmott (2005) show that the Black-Scholes hedge is quite robust to misspecification of this parameter, and in fact you can profit safely from option misprices even if your estimate of the volatility is not particularly close. The maximal utility and minimal variance hedges both require estimates of five unobserved parameters, while the adjusted Black-Scholes hedge requires only two. For this reason, it is reasonable 
to suggest that the profit distributions for the three strategies may be effected differently by parameter misspecification. We study this by generating 10000 stock trajectory pairs with 500 uniform rebalancing times for each strategy, and each value of a certain parameter. We use the parameters of Table 3.7, unless otherwise specified.

Tables 3.9-3.13 summarize the results on the resulting profit distributions. We can see that the adjusted Black-Scholes hedge profit standard deviation is much more sensitive to misspecification of the $\eta$ and $\sigma$ parameters, and of course, does not differ for different values of the other parameters. The two other strategies are less sensitive to misspecification of the volatility parameters, which is the investor's reward for having to estimate an additional three parameters. These three parameters do not seem to have much of an impact on the profit distributions. This should be reassuring to an investor, due to the notorious difficulty in estimating the drift terms. However, it is not entirely clear how to interpret these results. Comparing the mean profits with the standard deviations, it is clear that losses, even significant ones, are entirely possible here. For this reason, it is reasonable to evaluate the robustness of the strategies in terms of the effect on the investor's terminal utility. We do this next. 


\begin{tabular}{|c|c|c|c|}
\hline$\eta^{h}$ & Optimal & Minimum Local Variance & Black-Scholes \\
\hline 0.05 & $\begin{array}{l}\text { Mean: } 970.90 \\
\text { Std: } 2045.00 \\
\text { Median: } 2099.00\end{array}$ & $\begin{array}{l}\text { Mean: } 970.93 \\
\text { Std: } 2045.90 \\
\text { Median: } 2099.60\end{array}$ & $\begin{array}{l}\text { Mean: } 975.77 \\
\text { Std: } 1955.00 \\
\text { Median: } 1940.20\end{array}$ \\
\hline 0.1 & $\begin{array}{l}\text { Mean: } 975.17 \\
\text { Std: } 1921.70 \\
\text { Median: } 1904.60\end{array}$ & $\begin{array}{l}\text { Mean: } 975.28 \\
\text { Std: } 1925.40 \\
\text { Median: } 1915.90\end{array}$ & $\begin{array}{l}\text { Mean: } 983.68 \\
\text { Std: } 1840.80 \\
\text { Median: } 1689.60\end{array}$ \\
\hline 0.2 & $\begin{array}{l}\text { Mean: } 980.57 \\
\text { Std: } 1820.40 \\
\text { Median: } 1510.20\end{array}$ & $\begin{array}{l}\text { Mean: } 980.91 \\
\text { Std: } 1818.80 \\
\text { Median: } 1555.50\end{array}$ & $\begin{array}{l}\text { Mean: } 993.91 \\
\text { Std: } 2060.00 \\
\text { Median: } 1274.50\end{array}$ \\
\hline 0.3 & $\begin{array}{l}\text { Mean: } 984.33 \\
\text { Std: } 1946.90 \\
\text { Median: } 1207.80\end{array}$ & $\begin{array}{l}\text { Mean: } 984.90 \\
\text { Std: } 1901.50 \\
\text { Median: } 1275.60\end{array}$ & $\begin{array}{l}\text { Mean: } 1001.20 \\
\text { Std: } 2688.40 \\
\text { Median: } 1014.20\end{array}$ \\
\hline 0.4 & $\begin{array}{l}\text { Mean: } 987.61 \\
\text { Std: } 2248.10 \\
\text { Median: } 1059.00\end{array}$ & $\begin{array}{l}\text { Mean: } 988.39 \\
\text { Std: } 2128.40 \\
\text { Median: } 1115.30\end{array}$ & $\begin{array}{l}\text { Mean: } 1007.50 \\
\text { Std: } 3470.00 \\
\text { Median: } 879.68\end{array}$ \\
\hline
\end{tabular}

Table 3.9: The distributions of the total profit when hedging the sale of a bundle of 500 put options with the stock and option parameters given in Table 3.7, with different values for $\eta$. 


\begin{tabular}{|c|c|c|c|}
\hline$\sigma^{h}$ & Optimal & Minimal Variance & Adjusted Black-Scholes \\
\hline 0.05 & $\begin{array}{l}\text { Mean: } 996.12 \\
\text { Std: } 2236.70 \\
\text { Median: } 1169.60\end{array}$ & $\begin{array}{l}\text { Mean: } 996.80 \\
\text { Std: } 2172.00 \\
\text { Median: } 1222.40\end{array}$ & $\begin{array}{l}\text { Mean: } 1022.80 \\
\text { Std: } 3653.20 \\
\text { Median: } 935.13\end{array}$ \\
\hline 0.10 & $\begin{array}{l}\text { Mean:980.57 } \\
\text { Std: } 1820.40 \\
\text { Median:1510.20 }\end{array}$ & $\begin{array}{l}\text { Mean: } 980.91 \\
\text { Std: } 1818.80 \\
\text { Median: } 1555.50\end{array}$ & $\begin{array}{l}\text { Mean: } 993.91 \\
\text { Std: } 2060.00 \\
\text { Median: } 1274.50\end{array}$ \\
\hline 0.20 & $\begin{array}{l}\text { Mean: } 972.80 \\
\text { Std: } 1915.90 \\
\text { Median: } 1853.30\end{array}$ & $\begin{array}{l}\text { Mean: } 972.97 \\
\text { Std: } 1924.10 \\
\text { Median: } 1884.40\end{array}$ & $\begin{array}{l}\text { Mean: } 979.47 \\
\text { Std: } 1823.50 \\
\text { Median: } 1607.10\end{array}$ \\
\hline 0.30 & $\begin{array}{l}\text { Mean: } 970.20 \\
\text { Std: } 1991.90 \\
\text { Median: } 2004.30\end{array}$ & $\begin{array}{l}\text { Mean: } 970.32 \\
\text { Std: } 1999.00 \\
\text { Median: } 2027.00\end{array}$ & $\begin{array}{l}\text { Mean: } 974.65 \\
\text { Std: } 1886.10 \\
\text { Median: } 1800.60\end{array}$ \\
\hline 0.40 & $\begin{array}{l}\text { Mean: } 968.91 \\
\text { Std: } 2037.10 \\
\text { Median: } 2088.20\end{array}$ & $\begin{array}{l}\text { Mean: } 968.99 \\
\text { Std: } 2043.00 \\
\text { Median: } 2106.30\end{array}$ & $\begin{array}{l}\text { Mean: } 972.24 \\
\text { Std: } 1942.70 \\
\text { Median: } 1922.20\end{array}$ \\
\hline
\end{tabular}

Table 3.10: The distributions of the total profit when hedging the sale of a bundle of 500 put options with the stock and option parameters given in Table 3.7, with different values for $\sigma$. 


\begin{tabular}{|c|c|c|c|}
\hline$v^{h}$ & Optimal & Minimum Local Variance & Adjusted Black-Scholes \\
\hline-0.15 & $\begin{array}{l}\text { Mean: } 977.38 \\
\text { Std: } 1894.60 \\
\text { Median: } 1235.80\end{array}$ & $\begin{array}{l}\text { Mean: } 977.75 \\
\text { Std: } 1879.10 \\
\text { Median: } 1262.50\end{array}$ & $\begin{array}{l}\text { Mean: } 993.91 \\
\text { Std: } 2060.00 \\
\text { Median: } 1274.50\end{array}$ \\
\hline-0.05 & $\begin{array}{l}\text { Mean:978.81 } \\
\text { Std: } 1848.00 \\
\text { Median:1346.60 }\end{array}$ & $\begin{array}{l}\text { Mean: } 979.24 \\
\text { Std: } 1836.40 \\
\text { Median: } 1385.10\end{array}$ & $\begin{array}{l}\text { Mean: } 993.91 \\
\text { Std: } 2060.00 \\
\text { Median: } 1274.50\end{array}$ \\
\hline 0.05 & $\begin{array}{l}\text { Mean: } 980.57 \\
\text { Std: } 1820.40 \\
\text { Median: } 1510.20\end{array}$ & $\begin{array}{l}\text { Mean: } 980.91 \\
\text { Std: } 1818.80 \\
\text { Median: } 1555.50\end{array}$ & $\begin{array}{l}\text { Mean: } 993.91 \\
\text { Std: } 2060.00 \\
\text { Median: } 1274.50\end{array}$ \\
\hline 0.15 & $\begin{array}{l}\text { Mean: } 982.21 \\
\text { Std: } 1829.40 \\
\text { Median: } 1693.70\end{array}$ & $\begin{array}{l}\text { Mean: } 982.31 \\
\text { Std: } 1836.70 \\
\text { Median: } 1732.80\end{array}$ & $\begin{array}{l}\text { Mean: } 993.91 \\
\text { Std: } 2060.00 \\
\text { Median: } 1274.50\end{array}$ \\
\hline 0.25 & $\begin{array}{l}\text { Mean: } 983.20 \\
\text { Std: } 1869.70 \\
\text { Median: } 1849.40\end{array}$ & $\begin{array}{l}\text { Mean: } 983.00 \\
\text { Std: } 1880.30 \\
\text { Median: } 1881.10\end{array}$ & $\begin{array}{l}\text { Mean: } 993.91 \\
\text { Std: } 2066.00 \\
\text { Median: } 1274.50\end{array}$ \\
\hline
\end{tabular}

Table 3.11: The distributions of the total profit when hedging the sale of a bundle of 500 put options with the stock and option parameters given in Table 3.7, with different values for $v$. 


\begin{tabular}{|c|c|c|c|}
\hline$\mu^{h}$ & Optimal & Minimum Local Variance & Adjusted Black-Scholes \\
\hline-0.15 & $\begin{array}{l}\text { Mean: } 983.29 \\
\text { Std: } 1879.80 \\
\text { Median: } 1877.60\end{array}$ & $\begin{array}{l}\text { Mean: } 983.04 \\
\text { Std: } 1890.40 \\
\text { Median: } 1904.60\end{array}$ & $\begin{array}{l}\text { Mean: } 993.91 \\
\text { Std: } 2060.00 \\
\text { Median: } 1274.50\end{array}$ \\
\hline-0.05 & $\begin{array}{l}\text { Mean: } 982.35 \\
\text { Std: } 1832.30 \\
\text { Median:1709.60 }\end{array}$ & $\begin{array}{l}\text { Mean: } 982.42 \\
\text { Std: } 1840.20 \\
\text { Median: } 1746.90\end{array}$ & $\begin{array}{l}\text { Mean: } 993.91 \\
\text { Std: } 2060.00 \\
\text { Median: } 1274.50\end{array}$ \\
\hline 0.05 & $\begin{array}{l}\text { Mean: } 980.57 \\
\text { Std: } 1820.40 \\
\text { Median: } 1510.20\end{array}$ & $\begin{array}{l}\text { Mean: } 980.91 \\
\text { Std: } 1818.80 \\
\text { Median: } 1555.50\end{array}$ & $\begin{array}{l}\text { Mean: } 993.91 \\
\text { Std: } 2060.00 \\
\text { Median: } 1274.50\end{array}$ \\
\hline 0.15 & $\begin{array}{l}\text { Mean: } 978.65 \\
\text { Std: } 1852.20 \\
\text { Median: } 1333.70\end{array}$ & $\begin{array}{l}\text { Mean: } 979.08 \\
\text { Std: } 1839.90 \\
\text { Median: } 1366.80\end{array}$ & $\begin{array}{l}\text { Mean: } 993.91 \\
\text { Std: } 2060.00 \\
\text { Median: } 1274.50\end{array}$ \\
\hline 0.25 & $\begin{array}{l}\text { Mean: } 977.16 \\
\text { Std: } 1904.10 \\
\text { Median: } 1227.70\end{array}$ & $\begin{array}{l}\text { Mean: } 977.50 \\
\text { Std: } 1888.70 \\
\text { Median: } 1244.00\end{array}$ & $\begin{array}{l}\text { Mean: } 993.91 \\
\text { Std: } 2066.00 \\
\text { Median: } 1274.50\end{array}$ \\
\hline
\end{tabular}

Table 3.12: The distributions of the total profit when hedging the sale of a bundle of 500 put options with the stock and option parameters given in Table 3.7, with different values for $\mu$. 


\begin{tabular}{|c|l|l|l|}
\hline $\boldsymbol{\rho}^{\boldsymbol{h}}$ & \multicolumn{1}{|c|}{ Optimal } & Minimum Local Variance & Adjusted Black-Scholes \\
\hline $\mathbf{0 . 6 5}$ & Std: 1837.20 & Std: 1829.30 & Mean: 993.91 \\
& Median: 1427.80 & Median: 1467.90 & Std: 2060.00 \\
\hline $\mathbf{0 . 7 5}$ & Std:1877.90 & Std: 1865.90 & Median: 1274.50 \\
& Median: 1372.60 & Median: 1405.90 & Mean: 993.91 \\
\hline $\mathbf{0 . 8 5}$ & Std: 1939.00 & Std: 1927.10 & Std: 2060.00 \\
& Mean: 989.38 & Mean: 989.58 & Median: 1274.50 \\
\hline $\mathbf{0 . 9 5}$ & Std:2016.40 & Std: 2010.60 & Mean: 993.91 \\
& Median: 1327.70 & Median: 1348.81 & Std: 2060.00 \\
\hline & Mean:992.39 & Mean: 992.47 & Median: 1274.50 \\
\hline
\end{tabular}

Table 3.13: The distributions of the total profit when hedging the sale of a bundle of 500 put options with the stock and option parameters given in Table 3.7, with different values for $\rho$. 


\subsection{Comparing the Hedging Strategies - Robustness to Parameter Mis- specification - Utility Loss}

Our second means of evaluating the results of hedging with different parameter values comes from a utility indifference argument, similar to that used to arrive at the utility indifference price earlier. We borrow this methodology from Larsen and Munk (2012), who introduce the value function:

$$
J^{\lambda}(t, w, y)^{\pi}=-\frac{1}{\gamma} \mathbb{E}_{w, y, t}\left[\exp \left(-\gamma\left(W_{T}+\lambda h\left(e^{Y_{T}}\right)\right)\right)\right]
$$

We use the superscript $(\ldots)^{\pi}$ to designate that this function is to be evaluated using a particular hedging strategy, not necessarily the optimal strategy as in Eqn.(3.2). We can calculate the loss due to using a suboptimal hedging strategy by finding the amount of money added to the initial wealth when we hedge with a suboptimal strategy, that leaves us indifferent between this strategy and using the optimal hedging strategy. Our method here differs from that of Larsen and Munk (2012) only in that we do not present the loss as a fraction of the initial wealth. This is because with exponential utility functions, the loss is independent of initial wealth.

Definition 4. The utility loss due to a suboptimal strategy to hedge a position with $\lambda$ options with expiration time $T$ is the $L$ that solves:

$$
J^{\lambda}(t, w, y ;)=J^{\lambda}(t, w+L, y)^{\pi} .
$$

Note that the loss is not calculated as a fraction of the initial wealth, as it is in Larsen 
and Munk (2012). This is because we are only studying investors with exponential utility functions, and thus the results of solving Eqn.(3.8) will be independent of initial wealth. Our results have shown that an investor who plans to hedge with a correlated stock as a means of securing a profit via volatility arbitrage will have to accept significant risk. For this reason, the risk preferences of the investor are of the utmost importance, which justifies analysing the effect of misspecified hedging parameters on the expected utility of terminal wealth. We take the same stock and option parameters as in the previous section. The results are summarized in Tables 3.15-3.19. Once again, we note the sensitivity of the adjusted Black-Scholes strategy to misspecification of the volatility terms. While one of the advantages of the adjusted Black-Scholes strategy is that there is no need to specify $v, \mu$ or $\rho$, we can see how little the utility loss is due to misspecification of these parameters. It is also interesting to see how little utility loss there is from overestimating the correlation between the two stocks. It seems to be more important for an investor to choose a strongly correlated stock to hedge with in the first place, than to have an accurate estimate of exactly how correlated they are. These results seem to justify using the two more sophisticated strategies, even if the investor only possesses rough estimates of the three extra parameters. It seems difficult for an investor to justify utilizing the minimal variance hedge it does not result in notably smoother profit trajectories. In addition, it does not incorporate the risk preferences of the investor, which in such a risky environment is a critical flaw. For these reasons, it would 
seem the maximal utility strategy should be the preferred method of securing a profit from volatility arbitrage in this incomplete market setting.

\begin{tabular}{|c|c|c|c|}
\hline \multicolumn{3}{|c|}{ Loss Due to Misspecification } \\
\hline $\boldsymbol{\eta}$ & Maximal Utility & Minimal Variance & Adjusted Black-Scholes \\
\hline 0.05 & 71.09 & 71.09 & 40.55 \\
\hline 0.1 & 33.36 & 34.26 & 1.81 \\
\hline 0.2 & - & 0 & 33.36 \\
\hline 0.3 & 17.14 & 9.03 & 185.26 \\
\hline 0.4 & 79.16 & 52.24 & 432.51 \\
\hline
\end{tabular}

Table 3.14: Utility loss due to misspecification of $\eta$ when hedging the sale of 500 European put options. 


\begin{tabular}{|c|c|c|c|}
\hline \multicolumn{3}{|c|}{ Loss Due to Misspecification } \\
\hline $\boldsymbol{\sigma}$ & Maximal Utility & Minimal Variance & Adjusted Black-Scholes \\
\hline 0.05 & 71.09 & 56.73 & 492.99 \\
\hline 0.1 & - & 0 & 33.36 \\
\hline 0.2 & 35.16 & 36.95 & 2.71 \\
\hline 0.3 & 57.63 & 59.42 & 25.25 \\
\hline 0.4 & 71.09 & 72.88 & 42.35 \\
\hline
\end{tabular}

Table 3.15: Utility loss due to misspecification of $\sigma$ when hedging the sale of 500 European put options.

\begin{tabular}{|c|c|c|c|}
\hline \multicolumn{3}{|c|}{ Loss Due to Misspecification } \\
\hline $\boldsymbol{v}$ & Maximal Utility & Minimal Variance & Adjusted Black-Scholes \\
\hline-0.15 & 14.44 & 10.83 & 33.36 \\
\hline-0.05 & 5.42 & 2.71 & 33.36 \\
\hline 0.05 & - & 0 & 33.36 \\
\hline 0.15 & 1.81 & 3.61 & 33.36 \\
\hline 0.25 & 10.83 & 14.44 & 33.36 \\
\hline
\end{tabular}

Table 3.16: Utility loss due to misspecification of $v$ when hedging the sale of 500 European put options. 


\begin{tabular}{|c|c|c|c|}
\hline \multicolumn{3}{|c|}{ Loss Due to Misspecification } \\
\hline $\boldsymbol{\mu}$ & Maximal Utility & Minimal Variance & Adjusted Black-Scholes \\
\hline-0.15 & 13.54 & 16.24 & 33.36 \\
\hline-0.05 & 2.71 & 4.51 & 33.36 \\
\hline 0.05 & - & 0 & 33.36 \\
\hline 0.15 & 5.42 & 3.61 & 33.36 \\
\hline 0.25 & 16.24 & 13.54 & 33.36 \\
\hline
\end{tabular}

Table 3.17: Utility loss due to misspecification of $\mu$ when hedging the sale of 500 European put options.

\begin{tabular}{|c|c|c|c|}
\hline \multicolumn{4}{|c|}{ Loss Due to Misspecification } \\
\hline $\boldsymbol{\rho}$ & Maximal Utility & Minimal Variance & Adjusted Black-Scholes \\
\hline 0.65 & 3.61 & 3.60 & 33.36 \\
\hline 0.75 & 21.38 & 17.42 & 33.36 \\
\hline 0.85 & 40.34 & 37.19 & 33.36 \\
\hline 0.95 & 73.00 & 62.42 & 33.36 \\
\hline
\end{tabular}

Table 3.18: Utility loss due to misspecification of $\rho$ when hedging the sale of 500 European put options. 


\section{Chapter 4}

\section{NON-PROBABILISTIC OPTION PRICING}

\subsection{Introduction to Non-Probabilistic Models - BJN Model}

Britten-Jones and Neuberger (1996) identify what they believe to be a paradox in option pricing. The traditional basis for calculating prices, sophisticated probabilistic treatments (Black-Scholes and its modifications), conflicts with the idea of arbitrage, which is concerned only with events which are impossible or certain (in axiomatic probability theory, sets of measure 0 or 1 ). They create a model which allows stock prices to take discrete values along a trajectory, given by $\mathbf{S}:=\left(S_{i}\right)_{0 \leq i \leq N(\mathbf{S})}$, where $N(\mathbf{S})$ is the trajectory-dependent number of prices and $S_{i}$ is a positive number. The constraints imposed on possible trajectories are mild: they must begin at the current stock price $\left(S^{c}\right)$, the absolute value of the difference in consecutive stock prices must be less than $d$ (a maximum jump size), and the sum of the squares of consecutive price moves must be equal to $Q$ (all trajectories should have measured quadratic variation $Q$ ). Britten-Jones and Neuberger (1996) choose to use trajectories that move through $(\mathrm{v}, \mathrm{S})$ space, where $v_{i}$ is the amount of quadratic variation remaining in the trajectory at the i-th stock price (thus $v_{0}=Q$ and $v_{N(\mathbf{S})}=0$ ). This acts something like a "volatility adjusted time". Summarizing the requirements to be an 
element of the allowed trajectories set $P\left(S^{c}, Q, d\right)$ :

$$
\begin{aligned}
& \mathbf{S}=\left\{S_{0}, S_{1}, \ldots, S_{N(\mathbf{S})}\right\} \in\left(P\left(S^{c}, Q, d\right)\right. \text { iff: } \\
& S_{0}=S^{c} \\
& \left|\ln S_{i+1}-\ln S_{i}\right| \leq d \quad 0 \leq i \leq N(\mathbf{S})-1, \\
& \quad \sum_{i=1}^{N(\mathbf{S})-1}\left(\ln S_{i+1}-\ln S_{i}\right)^{2}=Q .
\end{aligned}
$$

Not we take the interest rate, $r=0$. With this set of allowable trajectories, we define a sequence of remaining volatilities $\left(v_{i}\right)_{0 \leq i \leq N(\mathbf{S})-1}$ by

$$
\begin{aligned}
& v_{0}=Q, \\
& v_{i}=v_{i-1}-\left(\ln S_{i+1}-\ln S_{i}\right)^{2} .
\end{aligned}
$$

The trades are assumed to occur at no cost at the prices in the trajectory sequence. Using arbitration arguments, they can then find an upper and lower bound for the value of a European option, with expiration time T, which in general will be tighter than the standard Merton bounds. To arrive at the bounds, we consider an investor who has sold a European call option at a price $V\left(v_{0}, S_{0}\right)$, and holds a number of the underlying stock given by $\mathbf{H}=H\left(v_{i}, S_{i}\right)_{0 \leq i \leq N(\mathbf{S})-1}$. The profit of the investor will be given by

$$
P \& L=V\left(v_{0}, S_{0}\right)-V\left(v_{N(\mathbf{S})}, S_{N(\mathbf{S})}\right)+\sum_{i=0}^{N(\mathbf{S})-1} H\left(v_{i}, S_{i}\right)\left(S_{i+1}-S_{i}\right) .
$$

If given a specific price $V\left(v_{0}, S_{0}\right), \mathbf{H}$ is an arbitrage strategy if it leads to an investor having a profit greater than or equal to 0 , with at least one possible trajectory leading 
to a profit greater than 0 . If we require that $\mathbf{H}$ is not an arbitrage strategy, we must have

$$
V\left(v_{0}, S_{0}\right) \leq \sup _{\pi}\left\{V\left(S_{T}\right)-\sum_{i=0}^{N(\mathbf{S})-1} H\left(v_{i}, S_{i}\right)\left(S_{i+1}-S_{i}\right)\right\} .
$$

Because this must hold for all strategies $\mathbf{H}$, we can define the minimum upper bound as

$$
\bar{V}\left(v_{0}, S_{0}\right) \equiv \inf _{H}\left\{\sup _{\pi}\left\{V\left(S_{T}\right)-\sum_{i=0}^{N(\mathbf{S})-1} H\left(v_{i}, S_{i}\right)\left(S_{i+1}-S_{i}\right)\right\}\right\} .
$$

Intuitively, in Eqn.(4.1), we are defining an upper bound for the option as being a price such that when an investor sells the option and uses the hedging strategy $\mathbf{H}$, the investor is guaranteed to cover the total option payoff. The total option payoff is given by the sum of the option payoff and hedging losses. In Eqn.(4.2) we then use the hedging strategy $\mathbf{H}$ which results in the smallest payout in the worst case scenario for the investor.

This formula for calculating option bounds is not practical for use as it involves a search over all possible stock trajectories and hedging strategies. Britten-Jones and Neuberger (1996) note that if there exists a function $\bar{V}(v, S)$ that satisfies Eqn.(4.2) for all $S$ and $v$ in the function's domain, then the upper bound on the value of the option when the stock price is $S_{i}$ and the reaming volatility is $v_{i}$ must be $\bar{V}\left(v_{i}, S_{i}\right)$. This allows us the write out the problem in Eqn.(4.2) as a dynamic programming problem with the Bellman equation

$$
V\left(v_{i}, S_{i}\right)=\inf _{h}\left\{\sup \left[V\left(v_{i+1}, S_{i+1}\right)-h\left(S_{i+1}-S_{i}\right)\right]\right\}
$$


They define a control variable $z_{i}$ representing the growth between adjacent prices

$$
S_{i+1}=S_{i} \exp \left(z_{i}\right)
$$

meaning we can interpret the prices as one state variable, while the remaining volatility in a trajectory is the other state variable which evolves according to

$$
v_{i+1}=v_{i}-z_{i}^{2}
$$

and so we can rewrite the Bellman equation as

$$
\bar{V}\left(v_{i}, S_{i}\right)=\inf _{h}\left\{\sup \left[\bar{V}\left(v_{i}-z_{i}^{2}, S_{i}\right) \exp \left(z_{i}\right)-h S_{i}\left(\exp \left(z_{i}\right)-1\right)\right]\right\}
$$

with

$$
z_{i}^{2} \leq v_{i}, \quad z_{i}^{2} \leq d^{2}
$$

The terminal condition will be $\bar{V}\left(0, S_{N(\mathbf{S})}\right)=\left(S_{N(\mathbf{S})}-K\right)^{+}$of course, where $K$ is the strike price of the call option, while the initial conditions will be given by the choices for the state variables $S_{0}$ and $v_{0}$. Britten-Jones and Neuberger (1996) note that the min-max nature makes it a non-standard dynamic programming problem. They deal with this by finding the optimal hedging strategy and thus removing the minimizing aspect of the problem. We repeat here the heuristic argument of Britten-Jones and Neuberger (1996). We assume we have found the optimal hedge $h^{*}$. So we have

$$
\bar{V}\left(v_{i}, S_{i}\right)=\left\{\sup \left[\bar{V}\left(v_{i}-z_{i}^{2}, S_{i}\right) \exp \left(z_{i}\right)-h^{*} S_{i}\left(\exp \left(z_{i}\right)-1\right)\right]\right\}
$$


and therefore

$$
\bar{V}\left(v_{i}, S_{i}\right) \geq\left\{\left[\bar{V}\left(v_{i}-z_{i}^{2}, S_{i}\right) \exp \left(z_{i}\right)-h^{*} S_{i}\left(\exp \left(z_{i}\right)-1\right)\right]\right\} .
$$

We define a function $f$ to represent the difference between the left and right hand sides of Eqn.(4.3).

$$
f \equiv \bar{V}\left(v_{i}, S_{i}\right)-\left\{\left[\bar{V}\left(v_{i}-z_{i}^{2}, S_{i}\right) \exp \left(z_{i}\right)-h^{*} S_{i}\left(\exp \left(z_{i}\right)-1\right)\right]\right\}
$$

The function $f(z) \geq 0 \forall z$ with $f(0)=0$, and so it must be that

$$
f^{\prime}(0)=-\frac{\partial \bar{V}}{\partial S_{i}} S_{i}+h^{*} S_{i}=0
$$

and therefore

$$
h^{*}=\frac{\partial \bar{V}}{\partial S_{i}}
$$

So the problem be be written in the more standard way

$$
\bar{V}\left(v_{i}, S_{i}\right)=\left\{\sup \left[\bar{V}\left(v_{i}-z_{i}^{2}, S_{i}\right) \exp \left(z_{i}\right)-\frac{\partial \bar{V}}{\partial S_{i}} S_{i}\left(\exp \left(z_{i}\right)-1\right)\right]\right\},
$$

with the inequality constraint

$$
z_{i}^{2} \leq \min \left(v_{i}, d^{2}\right)
$$

and the terminal condition

$$
\bar{V}\left(0, S_{N(\mathbf{S})}\right)=\left(S_{N(\mathbf{S})}-K\right)^{+} .
$$

Britten-Jones and Neuberger (1996) procedure for determining the option price bounds is as follows. If we look at Eqn.(4.4), and take $z_{i}$ to be such that the 
supremum is achieved, then $\bar{V}\left(v_{i}, S_{i}\right)$ will be connected to the later value $\bar{V}\left(v_{i}-\right.$ $\left.z_{i}^{2}, S_{i} \exp \left(z_{i}\right)\right)$ by the linear relationship

$$
\bar{V}\left(v_{i}, S_{i}\right)=\left\{\left[\bar{V}\left(v_{i}-z_{i}^{2}, S_{i}\right) \exp \left(z_{i}\right)-\frac{\partial \bar{V}}{\partial S_{i}} S_{i}\left(\exp \left(z_{i}\right)-1\right)\right]\right\}
$$

We know that $\bar{V}\left(v_{i}, S_{i}\right)$ must be both an upper bound, and a lower upper bound. Hence, the line we are looking for will be one such that all its points lie are on or above the possible future option values $\bar{V}\left(v_{i}-z_{i}^{2}, S_{i}\right)$, and has the smallest possible value at $S_{i}$. The slope of this line will be $h^{*}$ and the value of the option will simply be the line value at $S_{i}$. This process, referred to as the convex hull algorithm, is shown graphically in Figure 4.1.

Britten-Jones and Neuberger (1996) construct the stock trajectories on a grid in $(\mathrm{v}, \mathrm{S})$ space with admissible prices $S^{l}=S_{0} e^{l \delta}$ and allowable remaining quadratic variations $v^{j}=j \delta^{2}$ for an arbitrary step size of $\delta$. The option value at a point on the $\operatorname{grid}(\mathrm{i}, \mathrm{j})$ is denoted $V_{j, l}$. From any point $(l, j)$, the reachable points are $\left(j-n^{2}, l+n\right)$ where

$$
n^{2} \leq \min \left(j, d^{2}\right),
$$

which enforces the jump constraint and the the non-negativity of remaining volatility. 


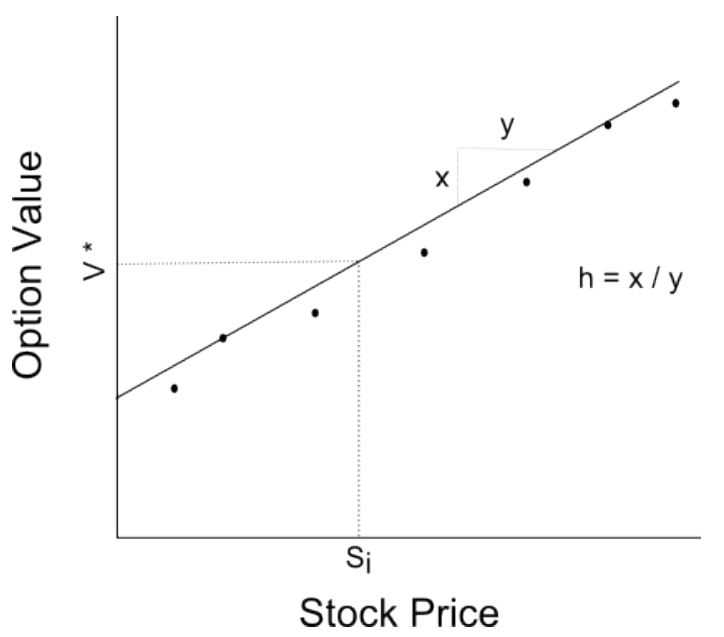

Figure 4.1: The graphical depiction of the convex hull pricing a particular node on a trajectory using all accessible node prices.

Britten-Jones and Neuberger (1996) explain that the derivation of the lower option bound, $\underline{V}$, is a trivial extension of the upper option bound. It is simply the negative of the upper bound for the option with payoff $V\left(0, S_{N}(\mathbf{S})\right)=-\left(S_{N(\mathbf{S})}-K\right)^{+}$. Obviously, whenever market prices for options appear outside of the no-arbitrage bounds, an investor could theoretically guarantee a profit by either buying or selling an option, and following the hedging strategy as determined by the grid. Of course, this assumes that the actual stock price trajectory that unfolds is an element of $P$. Of course, in reality we will be mapping trajectories onto a grid which will depend entirely on the choice of an arbitrary $\delta$. The mismatch between the actual stock trajectory and its mapping onto the grid can result in the investor failing to convert an arbitrage opportunity into a profit. The difficulty presented by mapping trajectories onto the grid inspires this next model, where we will use the parameters 
used to construct the grid to guide the investor's behaviour.

\subsection{The M0+Time Model}

In reality, there are transaction costs that act as an disincentive to constantly rebalancing a portfolio. It is fair to believe that an investor will only be motivated to rebalance once the stock price has changed by a certain amount, or some amount of time has passed since the last rebalancing. This acts as motivation for the M0+time model. We reuse the $\delta$ parameter from our implementation of the BJN model. Presumably, this will be much larger than the smallest possible price movement (1c). We can interpret this $\delta$ as the scale of stock movements which prompt the investor to rebalance. That is, any smaller price movement, relative to the previous rebalancing time, will be "ignored" by the investor. We assume the investor receives data from a stock price chart given by $x(t)$, where $t_{i}=d_{i} \Delta, d_{i} \in \mathbb{N}$, over some period of time $[0, T]$. Hence, $\Delta$ is the temporal resolution of the stock chart. As in the previous section, we take the interest rate to be $r=0$. We also assume there is a sequence of dynamically sampled times $\left\{r_{i}\right\} \subset\left\{t_{i}\right\}$ such that

$$
\delta \leq\left|x\left(r_{i+1}\right)-x\left(r_{i}\right)\right|, 0 \leq i \leq I, r_{I}=T .
$$

We take $S_{i}=x\left(r_{i}\right)$ and represent the trajectories as moving through $(r, S)$ space, where the r's represent times when the investor rebalances. A finite sequence of positive numbers will be in the admissible trajectories set, $A\left(\delta, S^{c}, m^{\max }, m^{\min }, q^{\max }, q^{\min }\right)$, 
according to

$$
\begin{aligned}
& \mathbf{S}=\left\{S_{0}, S_{1}, \ldots, S_{N(\mathbf{S})-1}\right\} \in A \text { iff: } \\
& S_{0}=S^{c} \\
& \delta \leq S_{i+1}-S_{i} \leq m^{\max } \delta \text { OR } m^{\min } \delta \leq S_{i+1}-S_{0} \leq-\delta, \\
& q^{\min } \Delta \leq r_{i+1}-r_{i} \leq \min \left(q^{\max } \Delta, T-r_{i}\right) .
\end{aligned}
$$

Obviously, $r_{i+1}-r_{i} \geq \Delta, \exists K$ such that $K \Delta=T$, and $S^{c}$ is the current stock price as in the previous section. We interpret $m^{\max } \in \mathbb{Z}$ to represent the largest possible upward stock move before the investor can rebalance and $m^{\text {min }} \in \mathbb{Z}$ to represent the largest possible downward stock move before the investor rebalances. We consider $t^{\text {min }} \in \mathbb{N}$ and $t^{\max } \in \mathbb{N}$ to represent the minimum and maximum amount of time we expect the investor to wait from the previous rebalancing time before rebalancing again.

Once again, the grid is constructed in $(r, S)$ space, with the allowable stock prices being given by $S^{l}=S_{0} \pm l \delta$ where $l \in \mathbb{Z}$, and the allowable times being given by $r^{j}=j \Delta$ where $j \in \mathbb{N}$. At a specific node $(j, l)$, the available nodes are $\left(j+q_{j}, l+m_{l}\right)$ where $q_{j} \in\left[q^{\min }, q^{\max }\right] \cap \mathbb{N}$ and $m_{l} \in\left[m^{\min },-\delta\right] \cup\left[\delta, m^{\max }\right] \cap \mathbb{Z}$.

Considering a European call option with strike K, the Bellman equation here will be will be very similar to that in the previous section,

$$
\begin{aligned}
\bar{V}\left(r_{i}, S_{i}\right) & =\inf _{h}\left\{\sup \left[\bar{V}\left(r_{i+1}, S_{i+1}\right)-h\left(S_{i+1}-S_{i}\right)\right]\right\} \\
& =\inf _{h}\left\{\sup \left[\bar{V}\left(r_{i}+q_{i} \Delta, S_{i}+m_{i} \delta\right)-h\left(m_{i} \delta\right)\right]\right\} .
\end{aligned}
$$


Repeating as we did in the previous section to find the optimal hedge, with $m_{i}$ here replacing $z_{i}$, gives

$$
h^{*}=\frac{\partial \bar{V}}{\partial S_{i}}
$$

which gives us the more standard dynamic programming problem

$$
\bar{V}\left(r_{i}, S_{i}\right)=\inf _{h}\left\{\sup \left[\bar{V}\left(r_{i}+q_{i} \Delta, S_{i}+m_{i} \delta\right)-\frac{\partial \bar{V}}{\partial S_{i}}\left(m_{i} \delta\right)\right]\right\}
$$

The terminal condition will be $\bar{V}\left(S_{N(\mathbf{S})}, T\right)=\left(S_{N(\mathbf{S})}-K\right)^{+}$of course, while the initial conditions will be given by the choices for the state variables $S_{0}$ and $r_{0}$. The convex hull algorithm performs identically as in the previous section, with the lone exception being the criteria for determining accessible nodes. It provides the hedging strategy $\mathbf{H}=H\left(r_{i}, S_{i}\right)_{0 \leq i \leq N(\mathbf{S})-1}$ as before.

\subsection{M0 Model - Parameter Estimation}

To price options an investor will need estimates of the parameters $m^{\min }, m^{\max }$, $q^{\min }$ and $q^{\max }$ which will depend on the choice of $\delta$. We now outline one possible method for the investor to estimate the necessary parameters from historical data. We assume the investor is estimating from $\mathrm{N}$ consecutive historical stock prices, uniformly taken at $\Delta$ intervals. We take the times $t_{i}^{h}$ to be the times of the historical prices $0 \leq t_{i}^{h} \leq T^{h}$ where $T^{h}$ is the time of the most recent historical price. We then select $r_{i}^{h} \subset t_{i}^{h}$, as rebalancing times, which fulfil Eqn.(4.6) from the historical stock price data (for example the past 6 months of hourly prices). The first rebalancing 
time in the past (which we call $r_{1}^{h}$ ) will correspond to the first price of the historical data being used for estimation. The second rebalancing time, $r_{2}^{h}=t_{2}^{h}$, where $t_{2}^{h}$ is the first time such that

$$
\delta \leq\left|S\left(t_{2}^{h}\right)-S\left(r_{1}^{h}\right)\right|, 0 \leq i \leq I, r_{I}=T .
$$

This process repeats with the Mth, and final, historical rebalancing time $r_{M}^{h}=t_{N}^{h}$. We can then set

$$
\begin{aligned}
q^{\min } & =\min \left(r_{i+1}^{h}-r_{i}^{h}\right), \\
q^{\max } & =\max \left(r_{i+1}^{h}-r_{i}^{h}\right) .
\end{aligned}
$$

These correspond to the minimum and maximum time the investor would have waited had he or she been rebalancing according to Eqn.(4.6) during the historical time period. It is in the estimation of these parameters that the investor will have to decide on their risk preferences. Larger values for the maximum parameters and smaller values for the minimum parameter values will mean a higher likelihood of the future trajectories matching the grids, but will also result in additional trajectories and thus larger price bounds. Note that what we are attempting to represent here, is an investor who rebalances as soon as his or her criteria for stock movement is met, and hence we only consider estimating $q^{\min }$ and $q^{\max }$. We could estimate $m^{\min }$ and $m^{\max }$ as the largest negative and positive stock price jumps (in terms of $\delta$ ) over an hour interval in the same way. Here, we will allow the investor to determine this to correspond with their own risk preferences. 


\subsection{Pricing Options using Historic Data}

We begin by taking $\delta=0.8, \Delta=1$ hour, $m^{\max }=2$ and $m^{\min }=-2$, and construct a grid corresponding to 56 hourly ticks in the future, or approximately a week's worth of activity. Using this data, we estimate $q^{\max }$ and $q^{\min }$ from the 6 months preceeding September 21, 2015 of hourly Facebook stock prices (Figure 4.2). Performing the method of parameter estimation described in the previous section yields $q^{\text {min }}=1$ and $q^{\max }=15$.

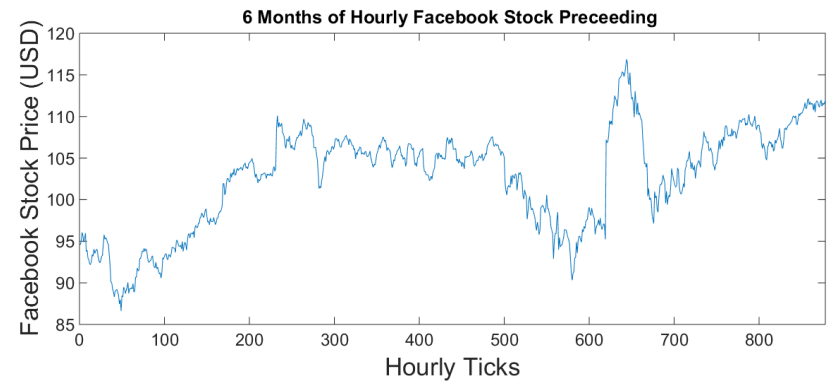

Figure 4.2: Six months of hourly Facebook stock prices taken between September 21, 2015 and March 21, 2016.

Using the convex hull algorithm described earlier, and the grid as outlined in Section 4.2, we can price European call options and compare to the ask prices for options with identical strikes and an expiration time of 7 days. This is done over a range of strikes in Figure 4.3. 


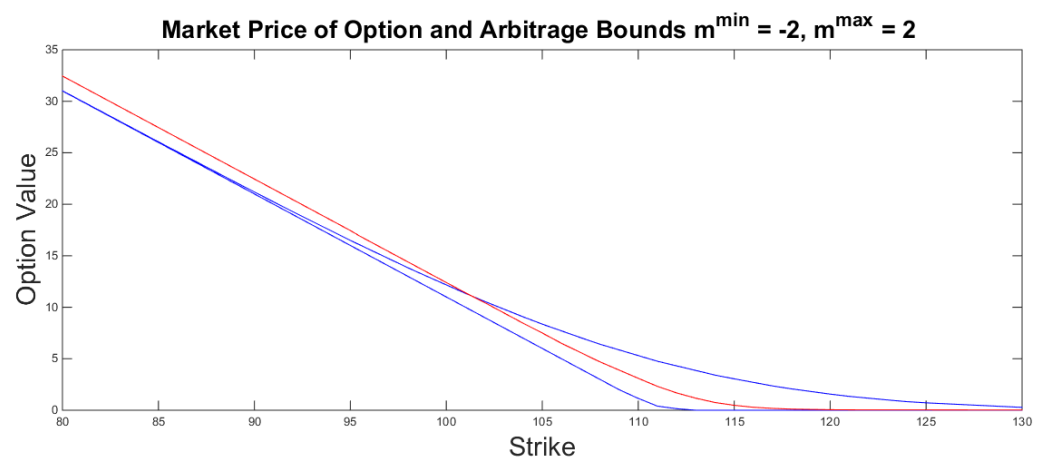

Figure 4.3: The arbitrage bounds for European call options for a risk taking investor compared with the market price. When the market price lies outside of the bounds there is the chance for arbitrage.

We can see for strikes below $\$ 100$, the market prices lie outside the arbitrage bounds. Thus, if the investor can sell an option at the ask price, he or she is guaranteed to be able to superhedge the resulting payoff and thus secure a profit, assuming the future stock trajectory matches one generated to create the arbitrage bounds. We can select a particular profitable strike price, $K=\$ 90$, and map the actual future stock price trajectory that occurred with the closest inside the pricing trajectory set on the grid. This allows us to determine what the investor's optimal hedge would be at each rebalancing time, and thus calculate their profit. In Figure 4.4 (top), we plot the future trajectory which unfolded and the element of the pricing trajectory set we map it to. We calculate the total profit according to

$$
P \& L=V_{0}-V_{T}+\sum_{i=1}^{M-1} H_{i}\left(S_{i+1}-S_{i}\right) .
$$

Here, the profit from selling the call option and hedging according to the mapped 
grid trajectory is calculated to be $\$ 1.01$. Our choice of $m^{\max }=2$ means that we assume the investor is capable of rebalancing before a price jump significantly above $\$ 1.60$ occurs since the last rebalancing. In the situation, this does does not cause any issues with the trajectory mapping because no particularly large price jumps occur. However, it is easy to imagine such a move occurring. The stock price data is hourly, of course, but it also considers the time between the market closing at the end of one day, and the market opening at the start of the next as a single hour. However, there are obviously reasons to believe larger jumps are possible between the interday prices and the intraday prices jumps. As an example, imagine that we were to see the 56 hourly prices of the Facebook stock that occurred between January 272016 and February 8, 2016 (Figure 4.4 (bottom)). There is a stock movement that greatly exceeds what $m^{\max }=2$ allows in the grid. It takes a while for the grid prices to "catch up" to the real stock prices here. It would not be reasonable for the investor to profit in this case. The investor can perform a basic statistical analysis to determine how much risk they wish to take. They can calculate what percentage of price moves in the past will exceed a particular choice of $m^{\min }$ and $m^{\max }$. For example, in the 6 months of hourly data shown in Figure 4.4 (top), a little over $5 \%$ of hourly stock moves exceed $\$ 1.60$, with most being not much more and thus not causing much deviation from the grid. Notably, most of these larger hourly stock movements occur between trading days, as we hypothesized. This suggests an obvious means of extending the model. This would be specifying certain time slices 
of the grid to correspond to the final hourly price of the day. Stock price movements originating from these nodes could have their own parameter values which would be estimated from past interday movements. This would allow the investor to include larger price movements without them dominating the entire grid and thus the price bounds.
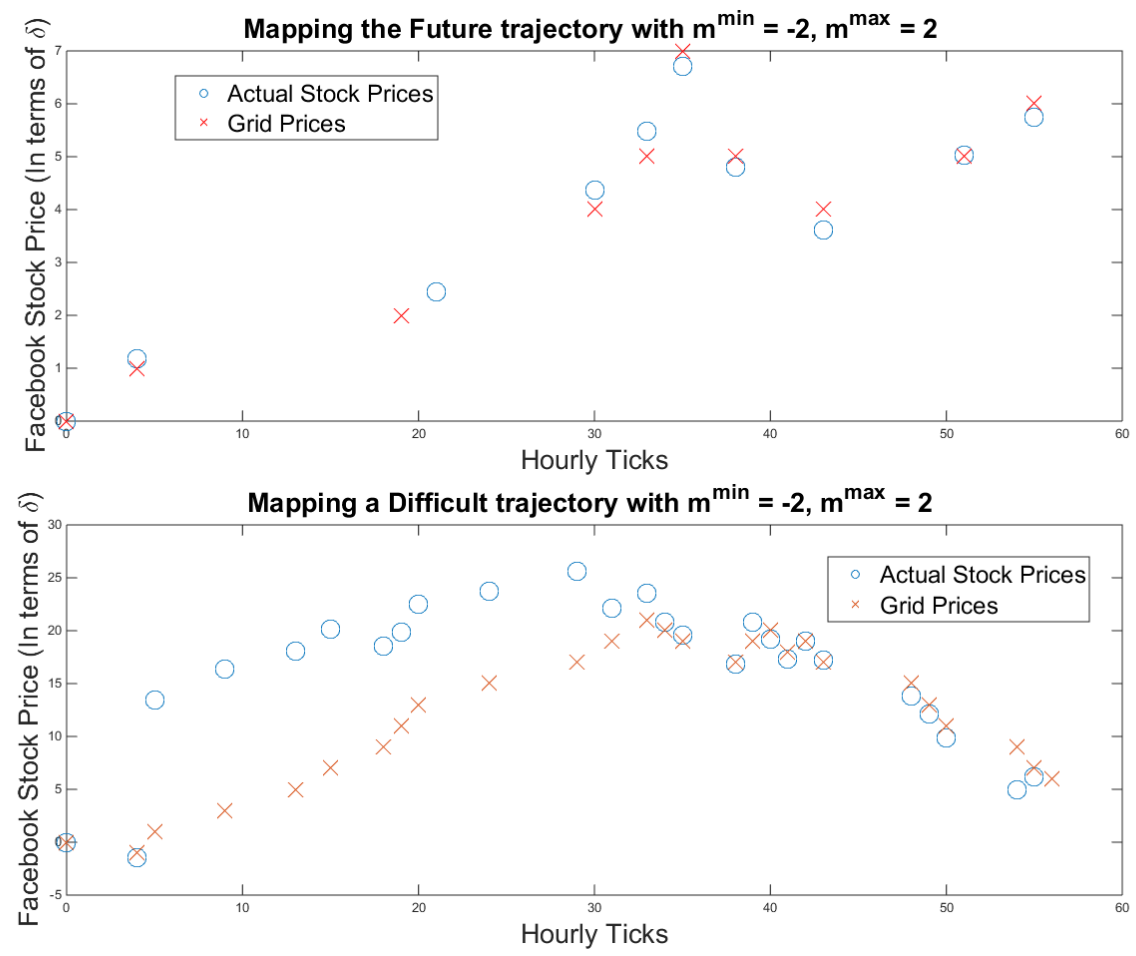

Figure 4.4: Top: Mapping the future trajectory onto the grid. We can see that the fairly close agreement allows an investor to be confident in obtaining a profit. Bottom: Mapping a difficult trajectory onto the grid. It is easy to see that there is much disagreement, and the investor would not be certain to profit. 
We can give the investor more latitude by repeating the previous analysis with

$$
\begin{gathered}
m^{\min }=-4, \\
m^{\max }=4 .
\end{gathered}
$$

The comparison of the new arbitrage bounds and the market ask prices is shown in Figure 4.5. We can see that the bounds are much larger and the investor has an opportunity for guaranteed profit only at the lowest strike. Of course, if the future trajectory had larger stock movements $(>\$ 1.60)$ the trajectory set with these new parameters would be more suitable. This is an illustration of the essential tradeoff the investor must make when pricing options in this framework. More cautious values for the parameter values result in an easier time accommodating the mapping of future trajectories, but result in less opportunities to find profit opportunities.

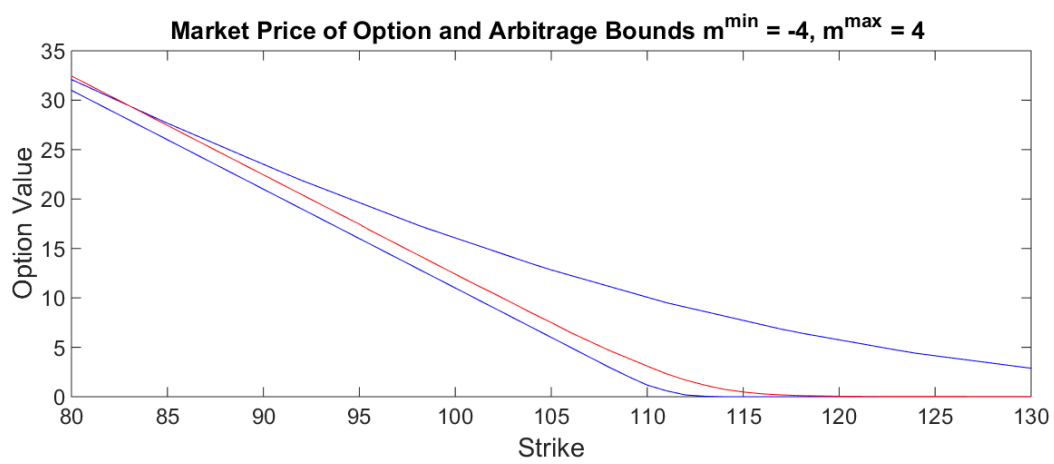

Figure 4.5: The arbitrage bounds for European call options for a more cautious investor compared with the market price. When the market price lies outside of the bounds there is the chance for arbitrage. 


\subsection{Volatility Arbitrage in BJN Framework}

We can look at the profit made while hedging in the Britten-Jones and Neuberger trajectory-based framework. Recall that in the BJN framework, every trajectory has the same realized quadratic variation. In this framework, we now attempt to create a situation analogous to Chapter 2. We consider an investor who is able to invert (through some iterative process) the current market price for a European call option and obtain an implied quadratic variation $\left(Q^{i}\right)$. The investor attempts to profit from a more accurate estimate for the future actual quadratic variation $\left(Q^{a}\right)$. Corresponding trajectory sets can be created for both quadratic variations, as well as pricing grids. We consider a situation where $Q^{i}>Q^{a}$, and thus, as long as $\delta$ is the same for both pricing grids, any node that is reachable on the grid corresponding to $Q^{a}$ should be reachable on that corresponding to $Q^{i}$. We take $S$ to be an arbitrary trajectory $S:=\left(S_{k}\right)_{0 \leqslant k \leqslant N(S)}$, where $N(S)$, the number of steps in the trajectory, will depend on the particular trajectory. We will denote the upper price bound of the option at the $k$ th stock price node by $\bar{V}_{k}$ and use the superscripts $(. .)^{a}$ and $(. .)^{i}$ to denote the price on the grid corresponding to the $Q^{a}$ price grid and $Q^{i}$ price grid respectively. The hedge at the $k$ th stock price node is denoted $H_{k}$.

We will consider the investor's profit to be the difference between the increase in the value of the portfolio and that of the upper bound for the implied value of the option. We will value the investor's option position using the $Q^{i}$ pricing grid, and so consider the following to be the mark-to-market profit 
If the investor hedges using the $Q^{a}$ grid, the profit is guaranteed to be within a certain range.

Theorem 6. If the investor hedges using the $Q^{a}$ grid, the total profit, which we denote $\sum_{k=0}^{N(S)-1} d \Pi_{k}$, with $d \Pi_{k}$ being the $k+1$ th incremental profit, must lie in the interval

$$
\bar{V}_{0}^{i}-\bar{V}_{0}^{a} \leq \sum_{k=0}^{N(S)-1} d \Pi_{k} \leq \bar{V}_{0}^{i}-\underline{V}_{0}^{a}
$$

Proof. The incremental profit is given by

$$
d \Pi=H_{k}^{a}\left(S_{k+1}-S_{k}\right)-\left(\bar{V}_{k+1}^{i}-\bar{V}_{k}^{i}\right) .
$$

Therefore, looking at the convex hull pricing algorithm, we can say

$$
\exists S_{k+1} \text { s.t. } d \Pi=H_{k}^{a}\left(S_{k+1}-S_{k}\right)-\left(\bar{V}_{k+1}^{i}-\bar{V}_{k}^{i}\right)<0 .
$$

Summing up the profits after each of price jumps

$$
\begin{array}{r}
\sum_{k=0}^{N(S)-1} d \Pi=\sum_{k=0}^{N(S)-1}\left[H_{k}^{a}\left(S_{k+1}-S_{k}\right)-\left(\bar{V}_{k+1}^{i}-\bar{V}_{k}^{i}\right)\right]= \\
\sum_{k=0}^{N(S)-1} H_{k}^{a}\left(S_{k+1}-S_{k}\right)-\left(V_{N(S)}-\bar{V}_{1}^{i}\right),
\end{array}
$$

and since

$$
\bar{V}_{1}^{a}+\sum_{k=0}^{N(S)-1} H_{k}^{i}\left(S_{k+1}-S_{k}\right) \geq V_{N} .
$$

We get

$$
\sum_{k=0}^{N(S)-1} d \Pi \geq V_{N(S)}-\bar{V}_{1}^{a}+\bar{V}_{1}^{i}-V_{N(S)}=\bar{V}_{1}^{i}-\bar{V}_{1}^{a}
$$


We can also use obtain an upper bound for the profit by noting that

$$
\underline{V}_{1}^{a}+\sum_{k=0}^{N(S)-1} H_{k}^{i}\left(S_{k+1}-S_{k}\right) \leq V_{N(S)},
$$

and therefore

$$
\sum_{k=0}^{N-1} d \Pi \leq \bar{V}_{1}^{i}+V_{N(S)}-\bar{V}_{1}^{a}-V_{N(S)}=\bar{V}_{1}^{i}-\underline{V}_{1}^{a}
$$

These past few results are the BJN analogues to Theorem 1. We can also see that when the investor hedges according to the $Q^{i}$ grid, the incremental profit is guaranteed to be positive.

Theorem 7. If the investor hedges using the $Q^{i}$ grid, the total profit, which we denote $\sum_{k=0}^{N(S)-1} d \Pi_{k}$, with $d \Pi_{k}$ being the $k+1$ th incremental profit, must be positive

$$
d \Pi_{k}=H_{k}^{i}\left(S_{k+1}-S_{k}\right)-\left(\bar{V}_{k+1}^{i}-\bar{V}_{k}^{i}\right) \geq 0 .
$$

Proof. The incremental profit now will be given by

$$
d \Pi=H_{k}^{i}\left(S_{k+1}-S_{k}\right)-\left(\bar{V}_{k+1}^{i}-\bar{V}_{k}^{i}\right) .
$$

The calculation of the option prices with the convex hull algorithm (Eqn.(4.5)) requires that

$$
H_{k}^{i}\left(S_{k+1}-S_{k}\right)+\bar{V}_{k}^{i} \geq \bar{V}_{k+1}^{i} \quad \forall \mathbf{S},
$$

and therefore,

$$
d \Pi=H_{k}^{i}\left(S_{k+1}-S_{k}\right)-\left(\bar{V}_{k+1}^{i}-\bar{V}_{k}^{i}\right) \geq 0 .
$$


So, when hedging using the amount determined by the $Q^{i}$ grid, the profit is guaranteed to be positive after each price jump. This is analagous to Theorem 2 . We can also look at the total profit in this situation obtained over the life of the option, given by the sum of the profits after each price jump:

$$
\begin{aligned}
\sum_{k=0}^{N(S)-1} d \Pi & =\sum_{\substack{k=0 \\
N(S)-1}}^{N(S)-1}\left[H_{k}^{i}\left(S_{k+1}-S_{k}\right)-\left(\bar{V}_{k+1}^{i}-\bar{V}_{k}^{i}\right)\right] \\
& =\sum_{k=0}^{i(S)} H_{k}^{i}\left(S_{k+1}-S_{k}\right)-\left(\bar{V}_{N(S)}^{i}-\bar{V}_{0}^{i}\right) .
\end{aligned}
$$

Since

$$
\bar{V}_{0}^{a}+\sum_{k=0}^{N-1} H_{k}^{a}\left(S_{k+1}-S_{k}\right) \geq V_{N} \quad \forall \mathbf{S} .
$$

We can say that

$$
\sum_{k=0}^{N-1} d \Pi \geq\left(\bar{V}_{0}^{i}-\bar{V}_{0}^{a}\right)+\sum_{k=0}^{N-1}\left(H_{k}^{i}-H_{k}^{a}\right)\left(S_{k+1}-S_{k}\right) \quad \forall \mathbf{S} .
$$




\section{Appendix A}

\section{DELTA HEDGING AND VOLATILITY ARBITRAGE}

\section{Result 1: Incremental Profit when hedging with $\sigma^{a}$}

The incremental mark-to-market profit of an investor delta hedging using $\sigma^{a}$ is given by

$$
d \Pi_{t}=d V_{t}^{i}-\Delta_{t}^{a} d S_{t}-r\left(V_{t}^{i}-\Delta_{t}^{a} S_{t}\right) d t
$$

We can use Ito's lemma to write the profit as

$$
d \Pi_{t}=\frac{\partial V_{t}^{i}}{\partial t} d t+\frac{\partial V_{t}^{i}}{\partial S_{t}} d S_{t}+\frac{1}{2}\left(\sigma^{a}\right)^{2} S_{t}^{2} \frac{\partial^{2} V_{t}^{i}}{\partial S_{t}^{2}} d t-\Delta_{t}^{a} d S_{t}-r\left(V_{t}^{i}-\Delta_{t}^{a} S_{t}\right) d t
$$

Replacing the $d S_{t}$ terms with Eqn.(2.1) gives

$d \Pi_{t}=\frac{\partial V_{t}^{i}}{\partial t} d t+\mu S_{t}\left(\Delta_{t}^{i}-\Delta_{t}^{a}\right)+\frac{1}{2}\left(\sigma^{a}\right)^{2} S_{t}^{2} \frac{\partial^{2} V_{t}^{i}}{\partial S_{t}^{2}} d t-r\left(V_{t}^{i}-\Delta_{t}^{s} S_{t}\right) d t+\left(\Delta_{t}^{i}-\Delta_{t}^{a}\right) \sigma^{a} S_{t} d B_{t}$.

Using the Black-Scholes equation to replace the $\frac{\partial V_{t}^{i}}{\partial t} d t$ term gives

$$
d \Pi_{t}=\frac{1}{2}\left[\left(\sigma^{a}\right)^{2}-\left(\sigma^{i}\right)^{2}\right] S^{2} \frac{\partial^{2} V_{t}^{i}}{\partial S_{t}^{2}} d t+\left(\Delta_{t}^{i}-\Delta_{t}^{a}\right)\left((\mu-r) S_{t} d t+\sigma S_{t} d B_{t}\right)
$$

\section{Result 2: Total Profit distribution when hedging with $\sigma^{i}$}

As described in Section 2.2, the total profit when an investor hedges with $\sigma^{i}$ will be a random variable. The interested reader is referred to Ahmad and Wilmott (2005) who provide lengthy derivations of the expected value and variance of the 
total profit. Below we provide their result for the expected value

$$
\begin{array}{r}
P \& L_{T}=\frac{K e^{-r\left(T-t_{0}\right.}\left[\left(\sigma^{a}\right)^{2}-\left(\sigma^{i}\right)^{2}\right]}{2 \sqrt{2 \pi}} \int_{t_{0}}^{T} \frac{1}{\sqrt{\left(\sigma^{2}\right)\left(s-t_{0}\right)+\left(\sigma^{i}\right)^{2}(T-s)}} \\
\exp \left(-\frac{\ln \left(S_{0} / K\right)+\left(\mu-\frac{1}{2}\left(\sigma^{a}\right)^{2}\right)}{2\left[\left(\sigma^{a}\right)^{2}\left(s-t_{0}\right)+\left(\sigma^{i}\right)^{2}(T-s)\right]}\right) d s .
\end{array}
$$




\section{Appendix B}

\section{HEDGING ILLIQUID CLAIMS AND VOLATILITY ARBITRAGE}

\section{Result 1: Deriving the optimal hedge and utility indifference price}

We expect that the value function

$$
\begin{aligned}
J^{\lambda}(t, w, y) & =\sup _{\pi \in \mathcal{L}}\left(-\frac{1}{\gamma} \mathbb{E}_{w, y, t}\left[\exp \left(-\gamma\left\{W_{T}+\lambda h\left(e^{Y_{T}}\right)\right\}\right)\right]\right), \\
& =-\frac{1}{\gamma} e^{-\gamma W_{t} e^{r(T-t)}} g(T-t, y) .
\end{aligned}
$$

will satisfy the Hamilton-Jacobi-Bellman (HJB) equation

$$
\frac{\partial J^{\lambda}}{\partial t}+\sup _{\pi} \mathcal{M}^{\pi} J^{\lambda}=0
$$

where $\mathcal{M}^{\pi}$ is the Markov generator of price dynamics (Halperin \& Itkin, 2012) corresponding to a hedging strategy $\pi . \mathcal{M}^{\pi}$ acts on $J^{\lambda}$ by

$$
\mathcal{M}^{\pi} J^{\lambda}=(r W+\pi(\mu-r)) \frac{\partial J^{\lambda}}{\partial w}+\frac{1}{2} \sigma^{2} \pi^{2} \frac{\partial^{2} J^{\lambda}}{\partial w^{2}}+v \frac{\partial J^{\lambda}}{\partial y}+\frac{1}{2} \eta^{2} \frac{\partial^{2} J^{\lambda}}{\partial y^{2}}+\rho \eta \sigma \pi \frac{\partial^{2} J^{\lambda}}{\partial w \partial y}
$$

Since the function being maximized is simply quadratic with respect to $\pi$, we can solve by taking the derivative with respect to $\pi$ and setting it equal to 0 . This yields the optimal dynamic hedging strategy

$$
\pi=-\frac{\left[(\mu-r) \frac{\partial J^{\lambda}}{\partial w}+\rho \sigma \eta \frac{\partial^{2} J^{\lambda}}{\partial w \partial y}\right]}{\sigma^{2} \frac{\partial^{2} J^{\lambda}}{\partial w^{2}}} .
$$


It is easy to check that when $J^{\lambda}$ is replaced in the previous equation using Eqn.(B.1), we get the optimal hedging strategy as described in Theorem 3. Substituting this optimal hedging strategy into Eqn.(B.3) and (B.2) gives us an equation for the function $g(T-t, y)$ :

$$
-\dot{g}+\left(v-\frac{1}{2} \eta^{2}\right) g^{\prime}+\frac{1}{2} \eta^{2} g^{\prime \prime}-\frac{\left(\sigma \rho \eta g^{\prime}+(\mu-r) g\right)^{2}}{2 \sigma^{2} g}=0
$$

Following Henderson and Hobson (2001), we use the transformation

$$
g(T-t, y)=e^{\alpha(T-t)} G\left(T-t, y+\left(\delta-\frac{\eta^{2}}{2}\right) \tau\right)^{b}
$$

and take

$$
b=\frac{1}{1-\rho^{2}}, \alpha=\frac{(\mu-r)^{2}}{2 \sigma^{2}}, \delta=r+\eta\left(\frac{v-r}{\eta}-\rho \frac{\mu-r}{\sigma}\right)
$$

to convert Eqn.(B.4) into

$$
\dot{G}=\frac{1}{2} \eta^{2} G^{\prime \prime}
$$

with the boundary condition $G(0, y)=e^{-\gamma \lambda h\left(e^{y}\right)\left(1-\rho^{2}\right)}$. This is the linear heat equation with solution

$$
G(\tau, y)=\mathbb{E}\left[G\left(0, y+\eta Z_{\tau}^{G}\right)\right]
$$

for a Brownian motion $Z_{\tau}^{G}$. Hence, $g(T-t, y)=e^{-(\mu-r)^{2}(T-t) /\left(2 \sigma^{2}\right)}\left[\mathbb{E}\left(e^{-\lambda \gamma\left(1-\rho^{2}\right) h\left(S_{t} e^{\eta Z_{\tau}^{G}+\delta(T-t)-\frac{1}{2} \eta^{2}(T-t)}\right)}\right)\right]^{\left(1-\rho^{2}\right)^{-1}}$ which is Eqn.(3.4) in a slightly different form. 


\section{Result 2: Alternative Expression for Maximal Utility Hedge}

Evaluating the partial derivatives of $J^{\lambda}(t, w, y)$ in Eqn.(B.3)

$$
\begin{aligned}
& \frac{\partial J^{\lambda}}{\partial w}=-\gamma e^{r(T-t)} J^{\lambda}, \\
& \frac{\partial^{2} J^{\lambda}}{\partial w^{2}}=\gamma^{2} e^{2 r(T-t)} J^{\lambda}, \\
& \frac{\partial^{2} J^{\lambda}}{\partial w \partial y}=-\gamma e^{r(T-t)} \frac{\partial J^{\lambda}}{\partial y},
\end{aligned}
$$

and taking the derivative of both sides of the the expression in Definition 1 with respect to $y$ gives

$$
\frac{\partial J^{0}(t, w+\tilde{V}, y ;)}{\partial y}=\frac{J^{\lambda}(t, w, y)}{\partial y}
$$

and

$$
\frac{\partial J^{\lambda}(t, \tilde{w}, y)}{\partial y}=\frac{\partial J^{\lambda}(t, \tilde{w}, y)}{\partial \tilde{w}} \frac{\partial \tilde{V}}{\partial y}
$$

where

$$
\tilde{w}=w+\tilde{V}(t, y)
$$

Substituting all of these expressions for the partial derivatives of $J$ into Eqn.(B.4), and evaluating at $\tilde{w}$, gives the alternative form for the optimal hedge mentioned in Section 3.4. 


\section{REFERENCES}

Ahmad, R., Wilmott, P. (2005) Which Free Lunch Would You Like Today, Sir?: Delta Hedging, Volatility Arbitrage and Optimal Portfolios. Wilmott Magazine, Wilmott Magazine, pp 64-79.

Davis, M. (2000) Optimal Hedging with Basis Risk. Preprint, Technical University of Vienna

Forsyth, P.A., Vetzal, K.R., Wang, J., Windcliff, H.(2005) Hedging with a Correlated Asset: Solution of a Nonlinear Pricing PDE. Journal of Computational and Applied Mathematics, 200(1), pp 86-115.

Halperin, I., Itkin, A.(2012) Pricing Options on Illiquid Assets with Liquid Proxies using Utility Indifference and Dynamic-state hedging. arXiv:1205.3507

Henderson, V. (2002) Valuation of Claims on Nontraded Assets Using Utility Maximization. Math. Finance 12, pp 351-73.

Henderson, V. (2001b) Stock Based Compensation: firm-specific risk, efficiency, and incentives. Preprint, University of Oxford

Henderson, V., and Hobson, D.G. (2001) Real Options with Constant Relative Risk Aversion. J. Econ. Dynamics Control 27, pp 329-55. Mathematical Finance, Vol. 12, No.4, October, 2002. 
Henderson, V., and Hobson, D.G. (2002) Substitute Hedging. Risk 15, pp 71-75. Mathematical Finance, Vol. 12, No.4, October, 2002.

Hulley, H., McWalter, T.A. (2015) Quadratic Hedging of Basis Risk. J. Risk Financial Manag., 8, pp 83-102.

Jonsson, M., Nielsen, S.E., Poulsen, R. (2015) The Fundamental Theorem of Derivative Trading - Exposition, Extensions, and Experiments.

Larsen, L.S., Munk, C. (2012) The Costs of Suboptimal Dynamic Asset Allocation: General Results and Applications to Interest Rate Risk, Stock Volatility Risk, and Growth/Value Tilts. J. Econom. Dynam. Control, 36, pp 266-293.

McFarland, J. (2015) In top CEO pay, stock option grants falling out of favour. The Globe and Mail. Retrieved from http://www.theglobeandmail.com/reporton-business/careers/management/executive-compensation/ceo-paytrends/article24815769/

Monoyios, M. (2004) Performance of Utility-based strategies for Hedging Basis Risk. Quant. Finance, 4, pp 245-255.

Monoyios, M. (2007) Optimal Hedging and Parameter Uncertainty Appl. Math. Financ. 18, pp 331-351.

Monoyios, M. (2010) Utility-based Valuation and Hedging of Basis Risk with Partial Information Appl. Math. Financ. 17, pp 519-551. 
Papayiannis, A. (2010). Hedging Strategies: Complete and Incomplete Systems of Markets (Master's). University of Manchester. 